\title{
Mechanistic Insight into the [4 + 2] Diels-Alder Cycloaddition over First Row d-Block Cation-Exchanged Faujasites
}

\author{
Roderigh Y. Rohling, ${ }^{\dagger}$ Ionut C. Tranca, ${ }^{\ddagger}$ Emiel J. M. Hensen, ${ }^{* \dagger \odot}$ and Evgeny A. Pidko*, ${ }^{\dagger}, \|_{\odot}$ \\ ${ }^{\dagger}$ Inorganic Materials Chemistry group, Department of Chemical Engineering, and ${ }^{\ddagger}$ Energy Technology, Department of Mechanical \\ Engineering, Eindhoven University of Technology, P.O. Box 513, 5600 MB Eindhoven, The Netherlands
}

\section{Supporting Information}

ABSTRACT: The Diels-Alder cycloaddition (DAC) is a powerful tool to construct $\mathrm{C}-\mathrm{C}$ bonds. The $\mathrm{DAC}$ reaction can be accelerated in several ways, one of which is reactant confinement as observed in supramolecular complexes and Diels-Alderases. Another method is altering the frontier molecular orbitals (FMOs) of the reactants by using homogeneous transition-metal complexes whose active sites exhibit d-orbitals suitable for net-bonding orbital interactions with the substrates. Both features can be combined in first row d-block (TM) exchanged faujasite catalysts where the zeolite framework acts as a stabilizing ligand for the active site while confining the reactants. Herein, we report on a mechanistic and periodic DFT study on $\mathrm{TM}-(\mathrm{Cu}(\mathrm{I}), \mathrm{Cu}(\mathrm{II}), \mathrm{Zn}(\mathrm{II})$,

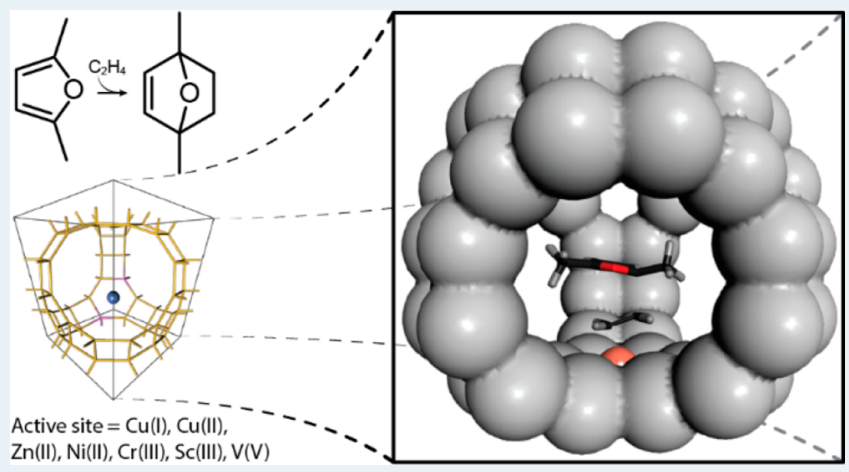
$\mathrm{Ni}(\mathrm{II}), \mathrm{Cr}(\mathrm{III}), \mathrm{Sc}(\mathrm{III}), \mathrm{V}(\mathrm{V})$ ) exchanged faujasites to elucidate the effect of d-shell filling on the DAC reaction between 2,5dimethylfuran and ethylene. Two pathways were found: one being the concerted one-step and the other being the stepwise twostep pathway. A decrease in d-shell filling results in a concomitant increase in reactant activation as evidenced by increasingly narrow energy gaps and lower activation barriers. For models holding relatively small d-block cations, the zeolite framework was found to bias the DAC reaction toward an asynchronous one-step pathway instead of the two-step pathway. This work is an example of how the active site properties and the surrounding chemical environment influence the reaction mechanism of chemical transformations.

KEYWORDS: DFT calculations, zeolite catalysis, 2,5-dimethylfuran, ethylene, property-activity relations

\section{INTRODUCTION}

The Diels-Alder cycloaddition $(\mathrm{DAC})^{1}$ is a powerful reaction to construct new $\mathrm{C}-\mathrm{C}$ bonds in the synthesis of compounds like drugs, macromolecules, and self-healing materials. ${ }^{2-8}$ The reaction takes place between a 1,3-diene and a moiety containing a double or triple bond (dienophile) and results in a cyclic product (Figure 1a). Depending on geometrical constraints and the symmetry of the orbitals that are involved, the reaction proceeds either via a one- or two-step reaction pathway to form, respectively, the two $\mathrm{C}-\mathrm{C}$ bonds simultaneously or via a stepwise mechanism. ${ }^{9-11}$

The activation energy $\left(E_{\mathrm{act}}\right)$ of this reaction is known to correlate with the energy and symmetry of the frontier molecular orbitals (FMOs) of the reactants. ${ }^{12-14}$ The reaction can proceed via the normal electron demand mechanism with a normal energy gap $\left(e_{\text {norm }}\right)$ defined by the difference between the $\mathrm{HOMO}_{\text {diene }}$ and $\mathrm{LUMO}_{\text {dienophile. Alternatively, the reaction }}$ can follow the inverse electron demand mechanism involving the inverse energy gap $\left(e_{\text {inv }}\right)$ determined by the $\mathrm{LUMO}_{\text {diene }}$ and $\mathrm{HOMO}_{\text {dienophile. }}$ A third mechanism is the neutral electron demand mechanism in which $e_{\text {norm }}=e_{\text {inv }}$. Ancillary species can be used to alter the FMO energies and the associated
HOMO-LUMO gap through orbital interactions, thereby affecting the DAC activation energy. ${ }^{15,16}$

It has recently been established that DAC chemistry is also useful for the conversion of furanic compounds to aromatics. ${ }^{5,17,18}$ The DAC reaction yields oxygen-containing bicyclic intermediates which is followed by dehydration yielding the aromatic compounds. ${ }^{19}$ Because furanics can be readily obtained from biomass-based feedstock, ${ }^{20,21}$ they can serve as intermediates in the production of biobased aromatics. $^{22}$ Such a Diels-Alder Cycloaddition (DAC)/ Dehydration(D) reaction (Figure $1 \mathrm{~b}$ ) process is regarded an appealing sustainable alternative to the existing petrochemical production routes. $^{23,24}$

Lewis $^{25-36}$ and Brønsted acid ${ }^{37-41}$ zeolite catalysts have been reported to be active for the DAC/D of biomass-derived furanic compounds. The perspective process targets such

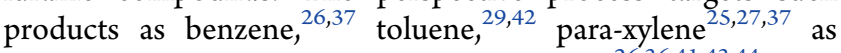
well as oxygenated aromatics compounds. ${ }^{26,36,41,43,44}$ The Lewis acidic zeolites such as alkali-exchanged fauja-

Received: August 30, 2018

Revised: November 18, 2018

Published: November 27, 2018 
a)

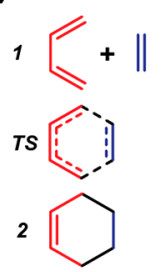

b)

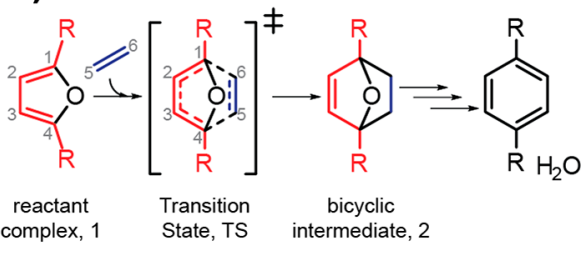

c)

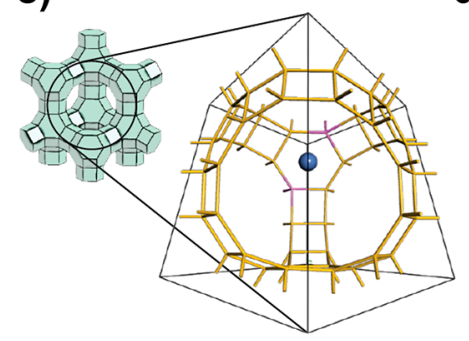

d)

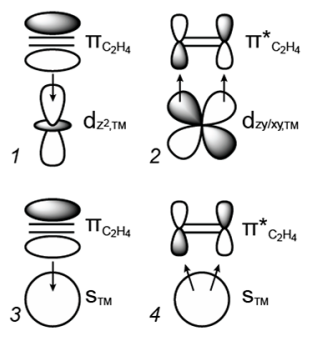

Figure 1. Generalized schemes for (a) the DAC and (b) DAC/D reaction. These reactions can be promoted by faujasite zeolite catalysts represented in this study by (c) a high-silica TM cation exchanged faujasite model (purple $=$ first row d-block cation, yellow $=$ zeolite framework with omitted oxygen atoms). The catalyst activates the substrates through (d) FMO-TM-orbital interactions.

sites $^{25-27,29,45}$ and lattice-modified Sn-, Ti-, Zr-and Zn-silicate zeolites $^{32,34,36,43,44,46}$ have been reported to be highly selective catalysts for these processes.

Previously, we explored the use of low-silica alkali-exchanged faujasite zeolites $\left(\mathrm{Si} / \mathrm{Al}=2.4 ; \mathrm{M}=\mathrm{Li}^{+}, \mathrm{Na}^{+}, \mathrm{K}^{+}, \mathrm{Rb}^{+}, \mathrm{Cs}^{+}\right.$; denoted MY) holding a high active site density in the DAC/D reaction of DMF with ethylene. ${ }^{25,26,45}$ Among the evaluated catalysts, one of the weakest Lewis acid zeolite catalysts (RbY) exhibited the lowest DAC-activation barrier. ${ }^{25,45}$ The catalytic effect, however, involved confinement rather than electronic modifications common for LA catalysis. ${ }^{45}$ Indeed, in MY catalysts, no alkali s-orbital $\cdots$ substrate-FMO overlap was found which could activate the reactants. ${ }^{26}$ Such an overlap can be established when d-elements are considered as active sites. Therefore, in this computational study, we focused on the effect of first row d-block (TM) cations stabilized in faujasite (FAU) micropores on the DAC reaction between DMF and $\mathrm{C}_{2} \mathrm{H}_{4}$ (Figure 1c). Because of the symmetry of both DMF and ethylene FMOs, $\sigma$-donor/acceptor and $\pi$-donor/acceptor interactions can be established with the TM cation d-orbitals upon coordination. Thus, the TM cations act both as Lewis acids and Lewis bases. That is, while exhibiting orbital overlap with the TM active site, the ethylene and DMF HOMOs act as $\sigma$-donor and $\pi$-donor while the ethylene and DMF LUMOs act as $\pi$-acceptor and $\sigma$-acceptor, respectively. Figure $1 \mathrm{~d}$ schematically illustrates the representative orbital interactions for ethylene, while the DFT-computed frontier orbitals for both substrates are shown in Figure S1.

TM-based catalysts are widely employed in DAC chemistry. Systems such as the TM coordination complexes, ${ }^{47-55}$ TMexchanged clays, $^{52}$ and TM-exchanged zeolites ${ }^{51}$ have been used earlier to catalyze DAC reactions. Among others, ${ }^{50,54,56}$ catalytic systems based on $\mathrm{Cu}(\mathrm{I}),{ }^{54,56} \mathrm{Cu}(\mathrm{II}),{ }^{56,57} \mathrm{Ni}(\mathrm{II}),{ }^{47,56}$ $\mathrm{Zn}(\mathrm{II}),{ }^{47,56} \mathrm{Sc}(\mathrm{III}),{ }^{47,51,55}$ and $\mathrm{Cr}(\mathrm{III})^{52,53,56}$ have been investigated. Typically, the reaction starts with a $\eta^{2} / \eta^{4}$-type coordination of the dienophile/diene to the metal ion. $^{48,49,54,56,58,59}$ The subsequent DAC mechanism usually involves an oxidative cyclization step that leads to a metallacycle intermediate followed by reductive elimination yielding the DAC adduct.

Combining TM cations as extra-framework active sites with zeolites results in the formation of microporous catalysts that can be seen as rigid enzymes or siliceous supramolecular complexes. Diels-Alderases ${ }^{60-63}$ and supramolecular complexes $^{64-66}$ show good performance in terms of activity via the confinement effect. Diels-Alderases bias a specific reaction channel by stabilizing the transition state (TS) in the protein matrix to achieve a high product stereoselectivity. Supramolecular catalysts also make use of noncovalent interactions to push the DAC reaction to proceed via a specific low-energy pathway showing an appropriate molecular fit with the molecular-sized cavity of the host. In comparison, the easyto-prepare and relatively cheap zeolite-based catalysts are wellknown for their ability to exert shape selectivity on chemical transformations within the confined microporous space while holding catalytically actives sites. ${ }^{67}$ Clearly, this is reminiscent of the shape selectivity induced by the catalytically active pocket in Diels-Alderases, or as enforced by a supramolecular environment.

It is therefore attractive to investigate the DAC reaction mechanism of DMF with ethylene and the electronic and steric factors governing the reactivity in TM-modified zeolite catalysts. In particular, we are interested in cations such as $\mathrm{Cu}(\mathrm{I}), \mathrm{Cu}(\mathrm{II}), \mathrm{Ni}(\mathrm{II}), \mathrm{Zn}(\mathrm{II}), \mathrm{Sc}(\mathrm{III})$ and $\mathrm{Cr}(\mathrm{III})\left(\mathrm{d}^{10}, \mathrm{~d}^{9}, \mathrm{~d}^{8}\right.$, $\mathrm{d}^{10}, \mathrm{~d}^{0}$ and $\mathrm{d}^{3}$, respectively) because of their known DAC activity and the varying d-electron configuration. Besides these practical systems, it is also interesting to consider a hypothetical model containing the pentavalent $\mathrm{V}(\mathrm{V})$ cation. Monomeric $\mathrm{V}(\mathrm{V})$ can typically be found to reside in zeolites as a terminal oxo species. ${ }^{68}$ However, in this work, we omitted the oxygen atom to solely focus on the effect of the strong Lewis acid/base properties of the $\mathrm{V}(\mathrm{V})$ cation.

\section{COMPUTATIONAL DETAILS}

Models. We studied the DAC reaction between DMF and ethylene over a periodic rhombohedral faujasite model containing an extraframework transition metal (TM) cation $(\mathrm{TM}=\mathrm{Cu}(\mathrm{I}), \mathrm{Cu}(\mathrm{II}), \mathrm{Zn}(\mathrm{II}), \mathrm{Ni}(\mathrm{II}), \mathrm{Cr}(\mathrm{III}), \mathrm{Sc}(\mathrm{III})$, and $\mathrm{V}(\mathrm{V})$; e.g., Ni(II)FAU). The cations were located in the 6membered ring of the sodalite cage, facing the supercage. This site is commonly referred to as the SII site. ${ }^{69}$ To ensure the overall charge neutrality of the model, an appropriate amount of $\mathrm{Al}^{3+}$ substitutions was placed as symmetrically as possible around the TM cation.

Methods. All calculations were carried out in the framework of density functional theory (DFT) with the gradient corrected PBE exchange-correlation functional and the projected-augmented-wave scheme (PAW) to describe the electron-ion interactions. ${ }^{70-74}$ Calculations were performed using the Vienna Ab-Initio Simulation Package (VASP). The DFT-D3 method with Becke-Johnson damping was used to account for long-range dispersive interactions. ${ }^{75,76}$ The k-point mesh was limited to the gamma-point. The plane-wave basis set cutoff energy was set to $500 \mathrm{eV}$. Cell-optimization was performed with a cutoff energy of $650 \mathrm{eV}$. Typically, a rootmean-square (RMS) force convergence criterion of $0.015 \mathrm{eV} /$ $\AA$ was employed. Models which contained TM cations with open d-shells were subjected to spin polarized calculations by enforcing the electron configurations using the appropriate settings in VASP. Different spin states of these TMFAU 
models were screened to find the energetically preferred electronic configurations. These were found to correspond to one, two, and three unpaired electrons for $\mathrm{Cu}(\mathrm{II}), \mathrm{Ni}$ (II), and Cr(III), respectively.

The transition states were located via a two-step procedure. First, a Climbing Nudged-Elastic-Band (CNEB) calculation $^{77,78}$ was performed to estimate the minimum energy pathway (MEP) (5 eV/ $\AA^{2}$ spring constant, maximum length hyper-vector between images $0.5 \AA$ ). For reactions proceeding via a two-step pathway, extra images were iteratively inserted to yield a MEP with finely distributed images. The accepted RMS force of the converged $\mathrm{CNEB}$ was $0.14 \mathrm{eV} / \AA$ or lower. Consecutively, geometry optimization of the identified transition states and possible intermediate was continued using the quasi-Newton procedure (maximal RMS $0.015 \mathrm{eV}$ / $\AA$ ). Vibrational frequencies were computed with the finite displacement method to confirm the nature of the stationary points.

Atomic Net Charges. The atomic net charges were computed in the framework of the QTAIM theory ${ }^{79}$ using VASP and the freely available scripts developed by Henkelman and co-workers ${ }^{80-83}$ (Bader charges). To obtain accurate Bader charges, the VASP-calculations were performed using a 2.5 times increased FFT-grid density. Charge integration was done in accordance with the method proposed by $\mathrm{Yu}$ and Trinkle ${ }^{83}$ with a vacuum level cutoff of $10^{-4} \mathrm{e}^{-} / \AA^{3}$. Tests with increasing grid density show that the convergence of the atomic charge was obtained at the employed values (accuracy of $0.01 \mathrm{e}^{-}$). The net charges per atom were obtained by referencing the calculated charges to the ideal valence charge of every atom. The Bader charges were compared with those obtained by employing the Density Derived Electrostatic and Chemical (DDEC6) method and were found to be similar. Therefore, in the text we report the Bader charges only whenever atomic or molecular net charges are discussed.

Bond Orders. (BO) were analyzed using the Chargemol code. ${ }^{84}$ We refer to the literature for extensive derivation of the equations necessary to compute the bond orders and carry out the underlying DDEC6 charge partitioning. ${ }^{85-87}$ Briefly, the bond order of an atom pair $A$ (in the unit cell) and $j$ (atoms in both unit cell and periodic images) is

$$
B_{A, j}=C E_{A, j}+\Lambda_{A, j}
$$

where $B_{A, j}$ is the bond order between atom $A$ and $j, \mathrm{CE}_{A, j}$ is the contact exchange and $\Lambda_{A, j}$ is the dressed exchange hole delocalization term. The term $\mathrm{CE}_{A, j}$ describes the electron exchange between atoms $A$ and $j$ in a material:

$$
\mathrm{CE}_{A, j}=2 \oint \frac{\vec{\rho}_{A}^{\mathrm{avg}}\left(\vec{r}_{A}\right) \cdot \vec{\rho}_{j}^{\mathrm{avg}}\left(\vec{r}_{j}\right)}{\vec{\rho}^{\mathrm{avg}}(\vec{r}) \cdot \vec{\rho}^{\mathrm{avg}}(\vec{r})} \rho(\vec{r}) d^{3} \vec{r}
$$

where any $\vec{\rho}_{i}^{\text {avg }}$ is the average spherical electron density of atom $i$ as a function of the atomic electron distribution and atomic spin magnetization density vector obtained through DDEC6based partitioning of the electron density. The term $\vec{\rho}^{\text {avg }}$ is the sum of all $\vec{\rho}_{i}^{\text {avg }}$ found in the material (unit cell + periodic images). Note that this equation deals with the dressed exchange hole, which is an adjusted (either more contracted or more diffuse) exchange hole to obtain more accurate bond orders. The second term in eq 1 . is the dressed exchange hole delocalization term defined according to eq 3 :

$$
\Lambda_{A, j}=X_{A, j}^{\text {coord.nr. }} X_{A, j}^{\text {pairwise }} X_{A, j}^{\text {con. }} \leq C E_{A, j}
$$

where $X_{A, j}^{\text {coord.nr. }}$ accounts for coordination number effects,

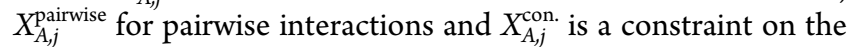
density-derived localization index, $B_{A, A}$. The latter is a matrix that equals the total number of the dressed exchange electrons in the material (unit cell + periodic images). These terms are constraints and scaling relationships to keep the bond orders well-behaved.

Density-of-States Analysis. The (partial) density of states (pDOS), the Crystal Orbital Hamilton Population and Crystal Orbital Overlap Population analysis were computed with the Lobster code, ${ }^{88-92}$ via transformation of the (plane) wave functions obtained by VASP into a localized basis set (STO). The evaluation of the (p)DOS in this way allows one to account for an analysis within the entire Brillouin zone and encompassing the entire electron density (i.e., summation of the local DOS adds up correctly to the value of the total DOS). In addition, for a consistent chemical interpretation of the pDOS independent of the atom position or orientation in the unit cell, an automatic rotation of the basis set was applied. The DOS values reported in this work are obtained by summation of both the up and down spin components.

Crystal Orbital Hamilton Population Analysis. The Crystal Orbital Hamiltonian Population (COHP) is related to the pDOS and allows partitioning of the electron density distribution into bonding, nonbonding, and antibonding interaction domains. ${ }^{88-92}$ The $-\mathrm{COHP}_{i j}(E)$ is defined in eq 4 as

$$
-\operatorname{COHP}_{i j}(E)=H_{i j} \sum_{n} c_{i}^{n} c_{j}^{n} \delta\left(E-E_{n}\right)
$$

where $H_{i j}$ represents the Hamiltonian matrix element between atomic orbitals $\varphi_{i}$ and $\varphi_{j}$, and $c_{i}$ and $c_{j}$ are the coefficients of these atomic orbitals in the molecular orbital $\psi_{n}\left(\psi_{n}=\sum_{i} c_{i}^{n} \varphi_{i}\right)$. A positive value for $-\mathrm{COHP}_{i j}(E)$ symbolizes a bonding electronic interaction between the atomic orbitals $i$ and $j$, while a negative value describes an antibonding interaction. A value of zero is associated with a nonbonding interaction. The integrated value of $-\mathrm{COHP}_{i j}(E), \mathrm{ICOHP}$, can be considered to be a measure for the bond strength. This formulation provides a good approximation of the bond energy as long as the repulsive energy of the nuclei is canceled by the doublecounted electrostatic interactions. ${ }^{93}$

Crystal Orbital Overlap Population Analysis. The Crystal Orbital Overlap Population $\left(\operatorname{COOP}_{i j}(E)\right)$ function introduced by Hoffmann ${ }^{94}$ can be defined according to eq 5 :

$$
\operatorname{COOP}_{i j}(E)=S_{i j} \sum_{n} c_{i}^{n} c_{j}^{n} \delta\left(E-E_{n}\right)
$$

where $S_{i j}=\left\langle\varphi_{i} \mid \varphi_{j}\right\rangle$ is the overlap of atomic orbitals $\varphi_{i}$ and $\varphi_{j}$. The values of $\operatorname{COOP}_{i j}(E)$ also quantify the bonding or antibonding character of the orbital interactions, but the electron density is now weighted by the atomic orbital overlap $S_{i j}$ instead of the bond energy overlap $H_{\mathrm{ij}}$. As a consequence, $\mathrm{COOP}_{i j}(E)$ cannot quantitatively analyze the contribution of the bonds to the total energy like the $-\mathrm{COHP}_{i j}(E)$ does. A quantitative evaluation of the bond strengths can nevertheless be obtained from the values of the integrated COOP (in unit of electrons).

\section{RESULTS}

The DAC reaction is initiated by coadsorption of the reactants resulting in the adsorbed state $\mathbf{1}\left(\mathrm{DMF}+\mathrm{C}_{2} \mathrm{H}_{4}+\mathrm{TMFAU} \rightarrow\right.$ 
1/TMFAU). One reactant adsorbs on the TM cation, and the other interacts via van der Waals interactions with the zeolite matrix. When DMF is $\eta^{2}$-coordinated to the TM cation and ethylene interacts with the framework, we refer to it as a DMFbased reaction with $\mathrm{DMF}$ as the primary adsorbent $\left(\mathbf{1}_{\mathrm{DMF}}\right)$. Conversely, we refer to an ethylene-based reaction when the $\eta^{2}$-coordinated ethylene is the primary adsorbent $\left(\mathbf{1}_{\mathrm{C} 2}\right)$.

The DAC reaction can proceed via two pathways. The first is a single-step (a)synchronous concerted DAC reaction with two nascent C … C bonds in the transition state (TS) yielding the bicyclic 1,4-dimethyl-7-oxabicyclo[2.2.1] hept-2-ene (2). The second pathway is a two-step reaction. This pathway starts from 1, reaches intermediate I via the first transition state TS1, and eventually results in 2 via the second transition state TS2. In TS1, the first C...C bond develops and in TS2 the second one. Figure 2 shows the DMF-based synchronous concerted one-step $(\mathrm{a}-\mathrm{c})$ and two-step $(\mathrm{d}-\mathrm{h})$ pathways over $\mathrm{Cu}(\mathrm{I})$ FAU and $\mathrm{Cu}(\mathrm{II}) \mathrm{FAU}$, respectively. A two-step mechanism with $\eta^{1}$ coordinated DMF in TS1 and no I and TS2 over Ni(II)FAU is

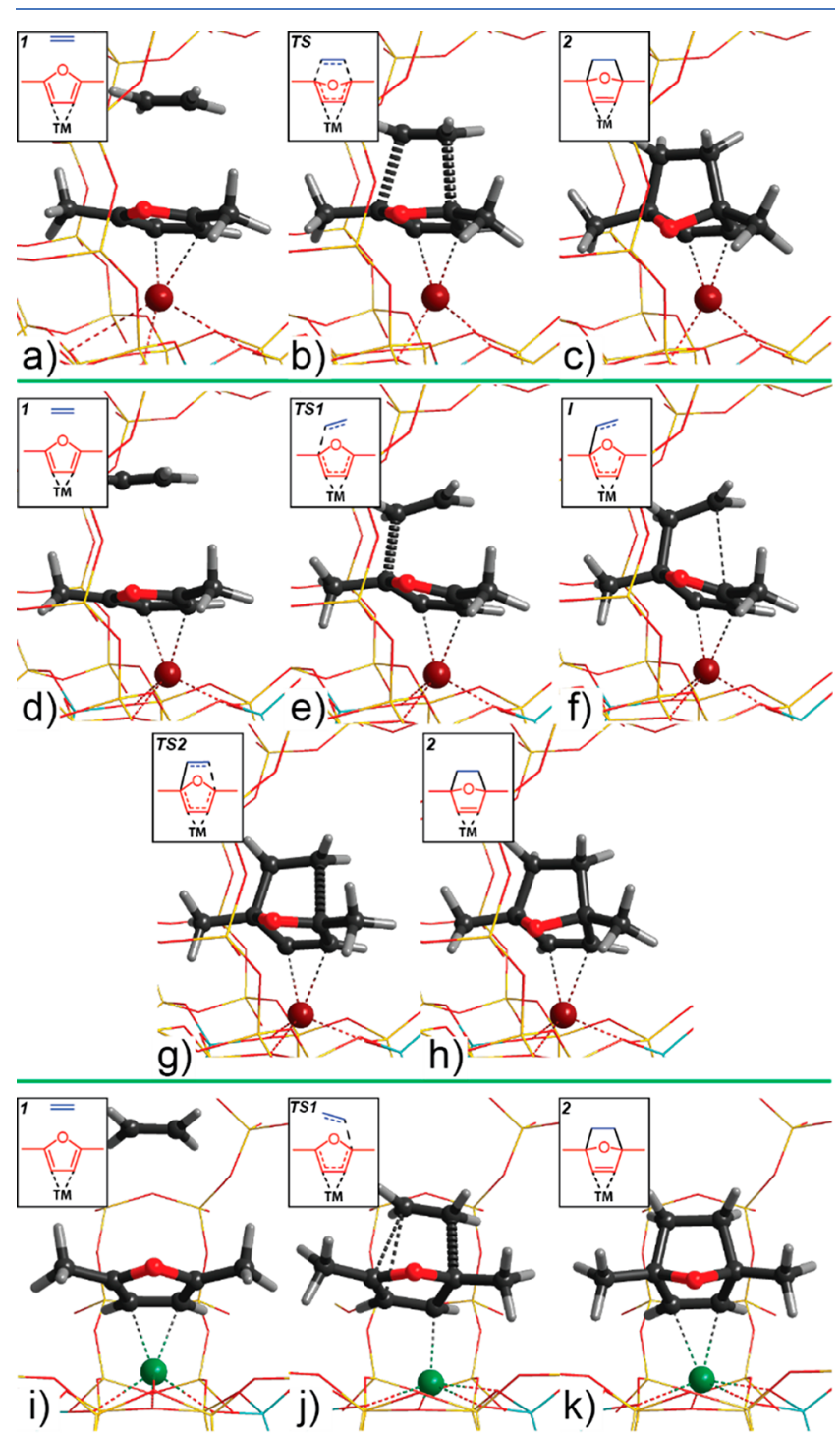

Figure 2. DMF-based synchronous concerted one-step pathway over $\mathrm{Cu}(\mathrm{I})$ FAU $(\mathrm{a}-\mathrm{c})$ and two-step pathway over $\mathrm{Cu}(\mathrm{II}) \mathrm{FAU}(\mathrm{d}-\mathrm{h})$. The DMF-based two-step pathway over Ni(II)FAU with $\eta^{1}$-coordinated DMF and lacking $\mathbf{I}$ and TS2 (i-k). displayed in panels $(\mathrm{i}-\mathrm{k})$. An example of the ethylene-based two-step pathway over $\mathrm{Cu}(\mathrm{II}) \mathrm{FAU}$ can be found in the Supporting Information (SI), Figure S2.

3.1. Adsorption Energies. The adsorption geometries consisted of either ethylene or DMF $\eta^{2}$-coordinated to the TM cation. DMF can coordinate via the $\mathrm{C} 2 / \mathrm{C} 3$ atoms or via the $\mathrm{C} 1 / \mathrm{C} 2$ atoms, referred to as DMF1 and DMF2, respectively. The adsorption energies $\left(E_{\mathrm{ads}}\right)$ are listed in Table 1 . The

Table 1. Ethylene (C2) and DMF Adsorption Energies ( $E_{\text {ads }}$, $\mathrm{kJ} / \mathrm{mol}$ )

\begin{tabular}{cccc} 
cation site & $E_{\text {ads, } \mathrm{C} 2}$ & $E_{\text {ads,DMF1 }}$ & $E_{\text {ads,DMF2 }}$ \\
$\mathrm{Cu}(\mathrm{I})$ & -152 & -130 & -155 \\
$\mathrm{Cu}(\mathrm{II})$ & -59 & -165 & \\
$\mathrm{Zn}(\mathrm{II})$ & -99 & $-142\left(-160^{a}\right)$ & \\
$\mathrm{Ni}(\mathrm{II})$ & -108 & $-142\left(-179^{a}\right)$ & \\
$\mathrm{Cr}(\mathrm{III})$ & -126 & -201 & -188 \\
$\mathrm{Sc}(\mathrm{III})$ & -109 & -191 & \\
$\mathrm{~V}(\mathrm{~V})$ & -145 & -276 & $-255^{a}$ \\
$\eta^{1}$-coordinated DMF & & \\
\hline
\end{tabular}

pDOS values of gas-phase ethylene, gas-phase DMF, $\mathbf{1}_{\mathrm{C} 2} /$ TMFAU, and $\mathbf{1}_{\mathrm{DMF}} / \mathrm{TMFAU}$ can be found in Figure 3. The pDOS of the TMFAU models without reactants can be found in Figure 4. The HOMO and LUMO of DMF and ethylene are visualized in Figure S1.

Note that we plotted the DOS associated with the hydrogen (dashed blue lines) and oxygen atoms (solid black) of the $\mathrm{C}_{2} \mathrm{H}_{4}$ or DMF molecules alongside the DOS of the $\mathrm{C}_{2 \mathrm{~s}}$ and $\mathrm{C}_{2 \mathrm{p}}$ (solid red) in Figure 3a. It is found that $\mathrm{H}$ and $\mathrm{O}$ contributions only increase the intensity of the bands already represented by $\mathrm{C}_{2 \mathrm{p}}$. The $\mathrm{C}_{2 \mathrm{~s}}$ lies typically too deep to be relevant (data not shown). Hence, in Figure $3 \mathrm{~b}$, we omitted the $\mathrm{H}$ and $\mathrm{O}$ contributions and solely focused on the TM cation 4s- and 3dorbitals and ethylene or DMF $\mathrm{C}_{2 \mathrm{p}}$-orbitals. Each panel represents a TM cation, with the two parts illustrating the DOS of $\mathbf{1}_{\mathrm{C} 2}$ and $\mathbf{1}_{\mathrm{DMF}}$. The primary adsorbent is marked by the asterisk.

Inspection of the $E_{\text {ads }}$ values indicates that DMF adsorption is generally about 1.5 to 2 times stronger than ethylene adsorption. Values of $E_{\mathrm{ads}, \mathrm{DMF1}}$ are between -130 to $-165 \mathrm{~kJ} /$ mol in $\mathrm{Cu}(\mathrm{I}) \mathrm{FAU}, \mathrm{Cu}(\mathrm{II}) \mathrm{FAU}$, and $\mathrm{Zn}$ (II)FAU, while those of ethylene are between -59 to $-152 \mathrm{~kJ} / \mathrm{mol}$. Creation of the DMF2 geometry in $\mathrm{Cu}(\mathrm{I}) \mathrm{FAU}$ yielded an adsorption energy $25 \mathrm{~kJ} / \mathrm{mol}$ stronger than the DMF1 geometry. In Cr(III)FAU and $\mathrm{Sc}(\mathrm{III}) \mathrm{FAU}, \mathrm{DMF}\left(\mathrm{C}_{2} \mathrm{H}_{4}\right)$ adsorption energies of -201 $(-126)$ and $-191(-109) \mathrm{kJ} / \mathrm{mol}$ are obtained, respectively. Calculations on the $\mathrm{V}(\mathrm{V}) \mathrm{FAU}$ model yielded an $E_{\mathrm{ads}, \mathrm{DMF} 1}$ of $-276 \mathrm{~kJ} / \mathrm{mol}\left(E_{\mathrm{ads}, \mathrm{C} 2}=-145 \mathrm{~kJ} / \mathrm{mol}\right)$. Optimization of the DMF2 adsorption geometry on $\mathrm{V}(\mathrm{V}) \mathrm{FAU}$ resulted in $\eta^{1}$ coordinated $\mathrm{DMF}$ with a strong $\mathrm{V}(\mathrm{V})-\mathrm{C} 1$ interaction.

Two DMF-adsorption geometries on the $\mathrm{Zn}(\mathrm{II})$ - and $\mathrm{Ni}(\mathrm{II})$-cation were obtained. In both $\mathrm{Zn}$ (II)FAU and $\mathrm{Ni}$ (II)FAU, $E_{\text {ads,DMF1 }}$ was $-142 \mathrm{~kJ} / \mathrm{mol}$, while those of $\mathrm{C}_{2} \mathrm{H}_{4}$ were -99 and $-108 \mathrm{~kJ} / \mathrm{mol}$, respectively. The alternative was $\eta^{1}$ coordination of DMF, predominantly coordinating via $\mathrm{C} 2$. These geometries resulted in adsorption energies that were 18 and $37 \mathrm{~kJ} / \mathrm{mol}$ stronger than for DMF1.

To understand the trends in adsorption energies, the $\sigma$ donor/acceptor and $\pi$-donor/acceptor properties of the TM cations and reactants have to be taken into account. The $\eta^{2}$ coordinated ethylene will act as an ethylene $\rightarrow$ TM $\sigma$-donor 
a)
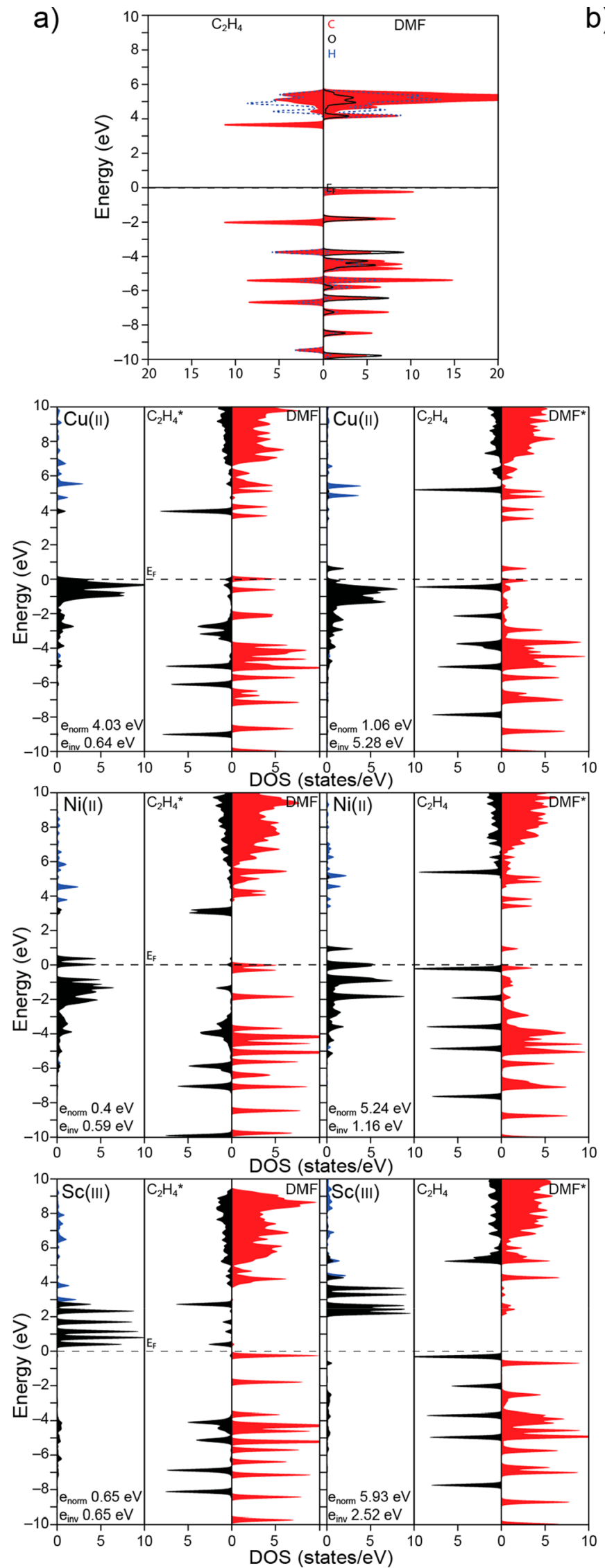

b)
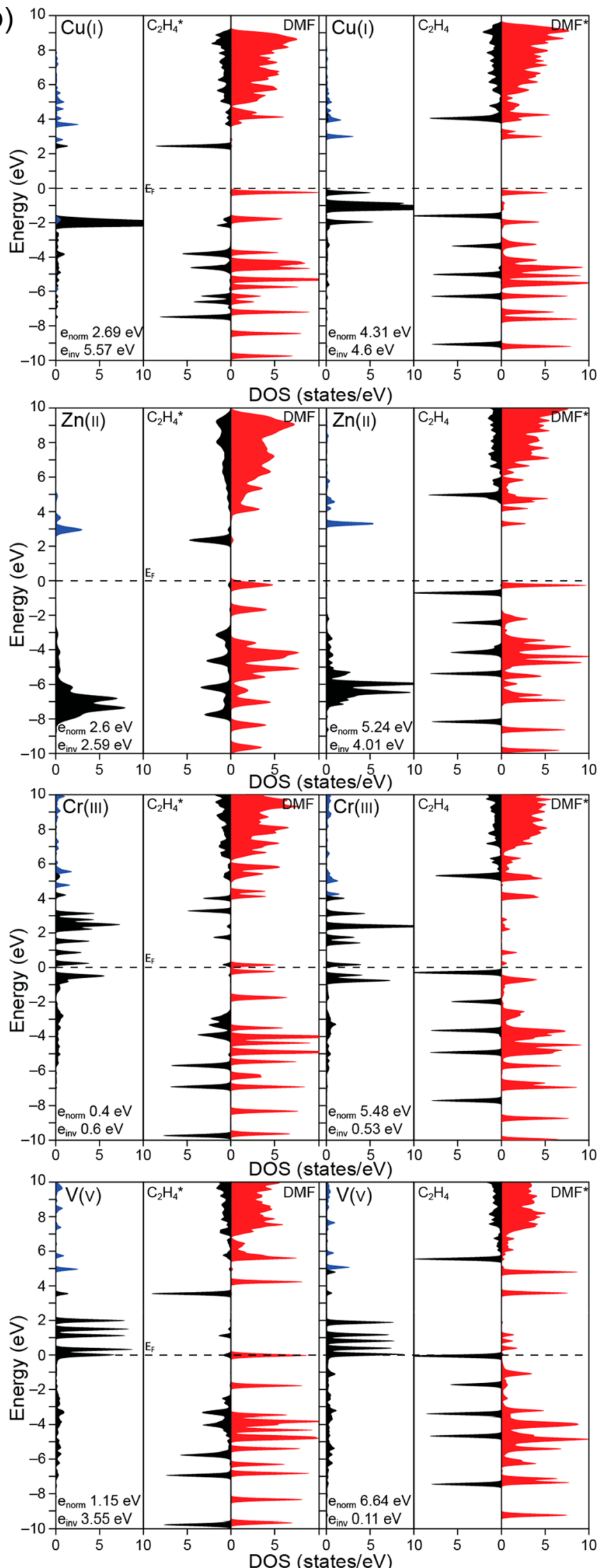

Figure 3. Density-of-States of gas phase $\mathrm{C}_{2} \mathrm{H}_{4}$ and DMF (a). In (b) the pDOS of each 1 with for d-block cations: black $=3 \mathrm{~d}-\mathrm{DOS}$ and blue $=4 \mathrm{~s}-$ DOS; ethylene: black $=2$ p-DOS; DMF: red $=2$ p-DOS. 


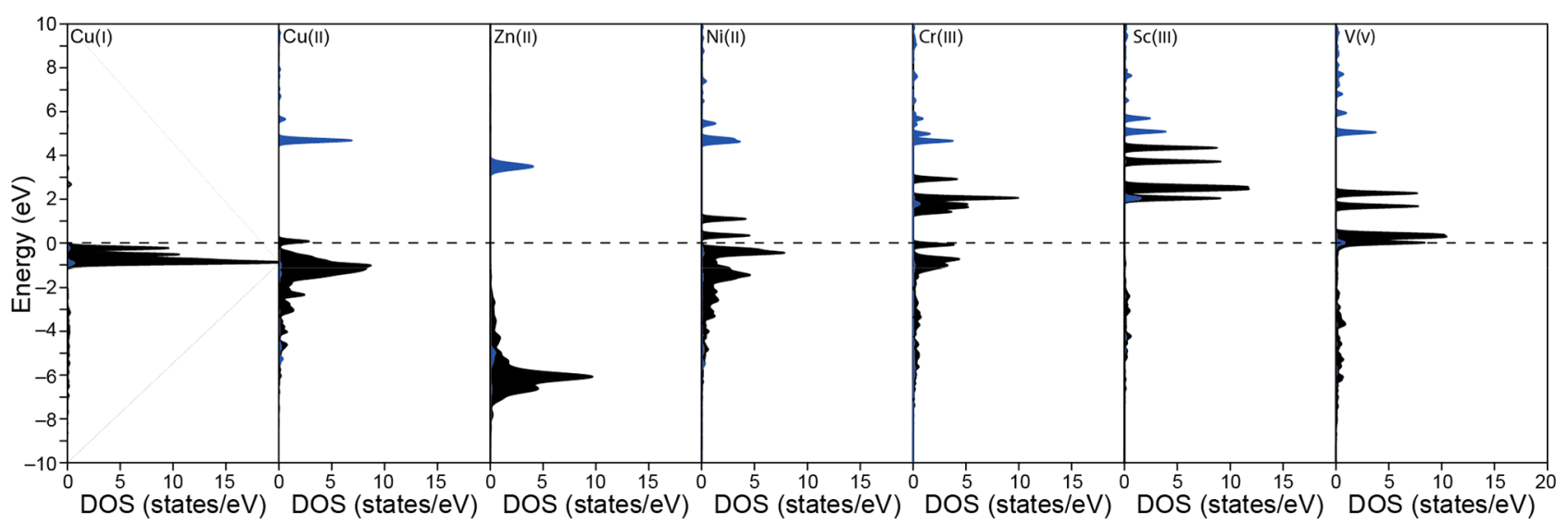

Figure 4. DOS of the TMFAU reference systems without reactants with the 3d-DOS (black) and 3s-DOS (blue).

- DMF-based reaction — Ethylene-based reaction

a)

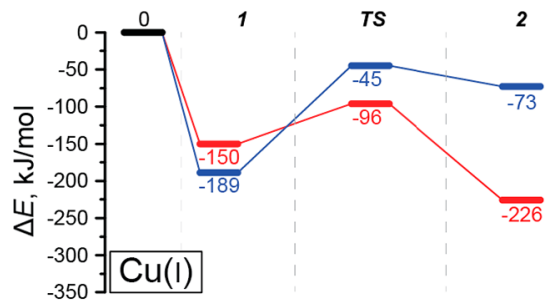

d)

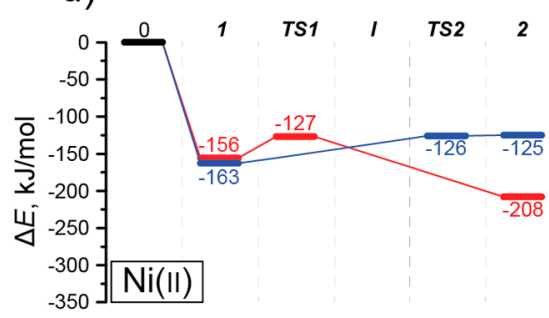

g)

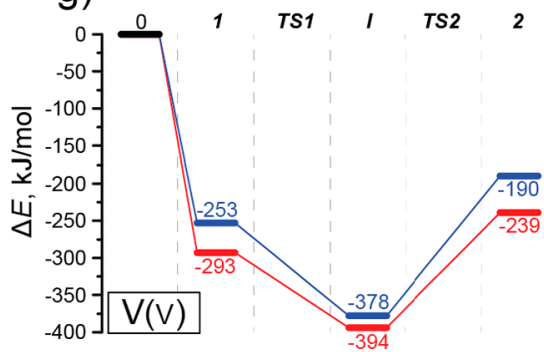

h) b)

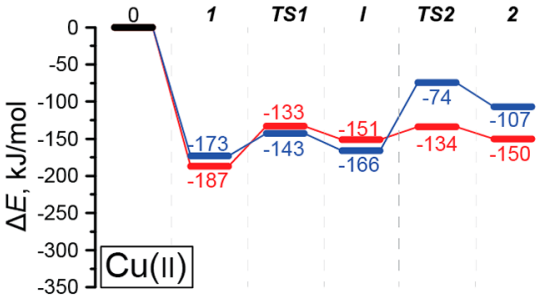

e) c)

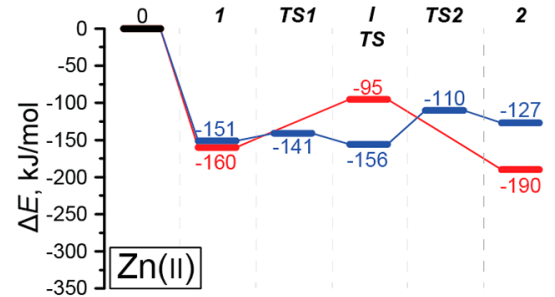

f)
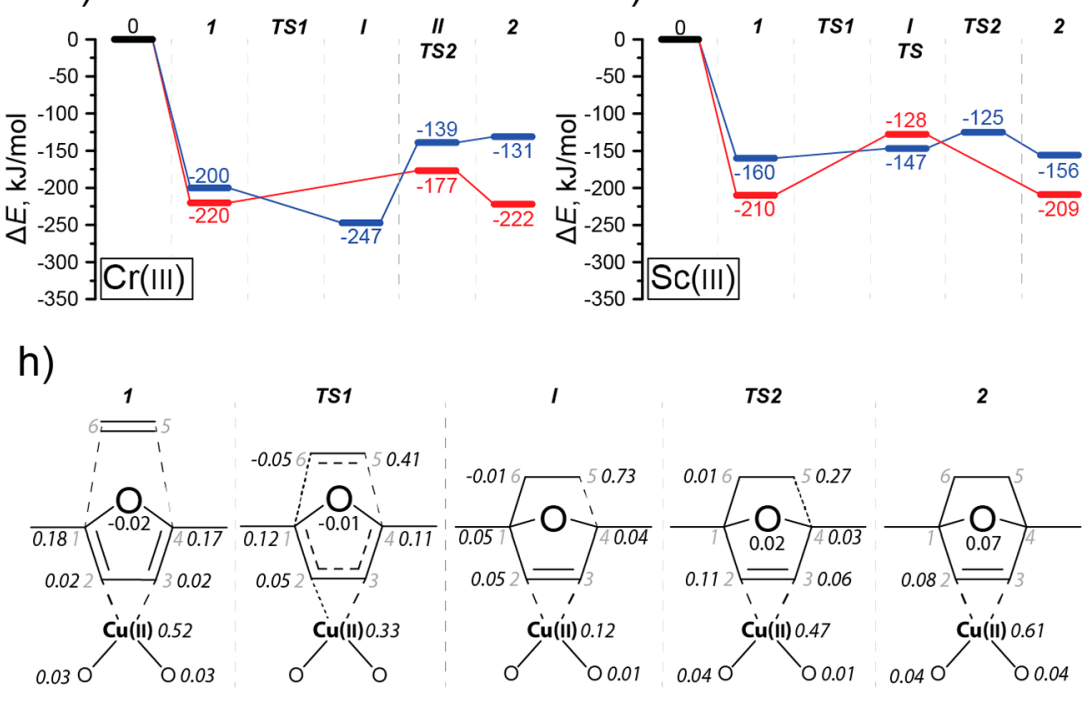

Figure 5. Reaction energy diagrams for the different TM-exchanged faujasites catalyzing either the ethylene- or DMF-based DAC-reaction, shown in blue and red, respectively $(\mathrm{a}-\mathrm{g})$. In $(\mathrm{h})$, the net spin density are reported for the $\mathrm{Cu}(\mathrm{II})$-catalyzed DMF-based DAC-reaction as the most extreme example of radical driven reactivity. When no value is provided, no significant net atomic spin density was found.

and $\mathrm{TM} \rightarrow$ ethylene $\pi$-acceptor via the HOMO and the LUMO, respectively. The DMF2 adsorption geometry will behave similarly. For $\eta^{2}$-coordinated DMF1, the symmetries of the HOMO and the LUMO make DMF1 a DMF1 $\rightarrow$ TM $\pi$ donor and TM $\rightarrow$ DMF1 $\sigma$-acceptor, respectively.

DMF1 $\rightarrow$ TM $\pi$-donation is expected to increase from $\mathrm{Cu}(\mathrm{II}), \mathrm{Cr}(\mathrm{III}), \mathrm{Sc}(\mathrm{III})$ to $\mathrm{V}(\mathrm{V})$ as the d-shells become emptier. $\mathrm{Cu}(\mathrm{I})$ and $\mathrm{Zn}(\mathrm{II})$ cannot participate in DMF1 $\rightarrow$ TM $\pi$-donation interactions as they both have a $\mathrm{d}^{10}$ configuration. However, the $\mathrm{Cu}(\mathrm{I})$ 3d-orbitals lie high enough in energy to allow TM $\rightarrow$ DMF1 $\sigma$-donation. The 3d-orbitals of $\mathrm{Zn}$ (II) are too low in energy. Although formally an empty orbital, the $4 \mathrm{~s}-$ orbital could allow for TM $\rightarrow$ DMF1 $\sigma$-donation interactions. $\mathrm{Cu}(\mathrm{I}), \mathrm{Cu}(\mathrm{II})$, and $\mathrm{Cr}(\mathrm{III})$ can facilitate TM $\rightarrow$ DMF1 $\sigma$ donation, resulting in an increase in interaction strength. $\mathrm{Sc}(\mathrm{III})$ and $\mathrm{V}(\mathrm{V})$ cannot provide $\mathrm{TM} \rightarrow \mathrm{DMF} 1 \sigma$-donation, but compensate for this by polarizing the reactants via strong electrostatic interactions.

A reasoning along similar lines holds for $\mathrm{C}_{2} \mathrm{H}_{4}$ and DMF2 as primary adsorbent. However, $\mathrm{C}_{2} \mathrm{H}_{4} / \mathrm{DMF} 2 \rightarrow \mathrm{TM} \sigma$-donation and $\mathrm{TM} \rightarrow \mathrm{C}_{2} \mathrm{H}_{4} / \mathrm{DMF} 2 \pi$-backdonation interactions now play a role. Consequently, the interaction of $\mathrm{C}_{2} \mathrm{H}_{4} / \mathrm{DMF} 2$ with 

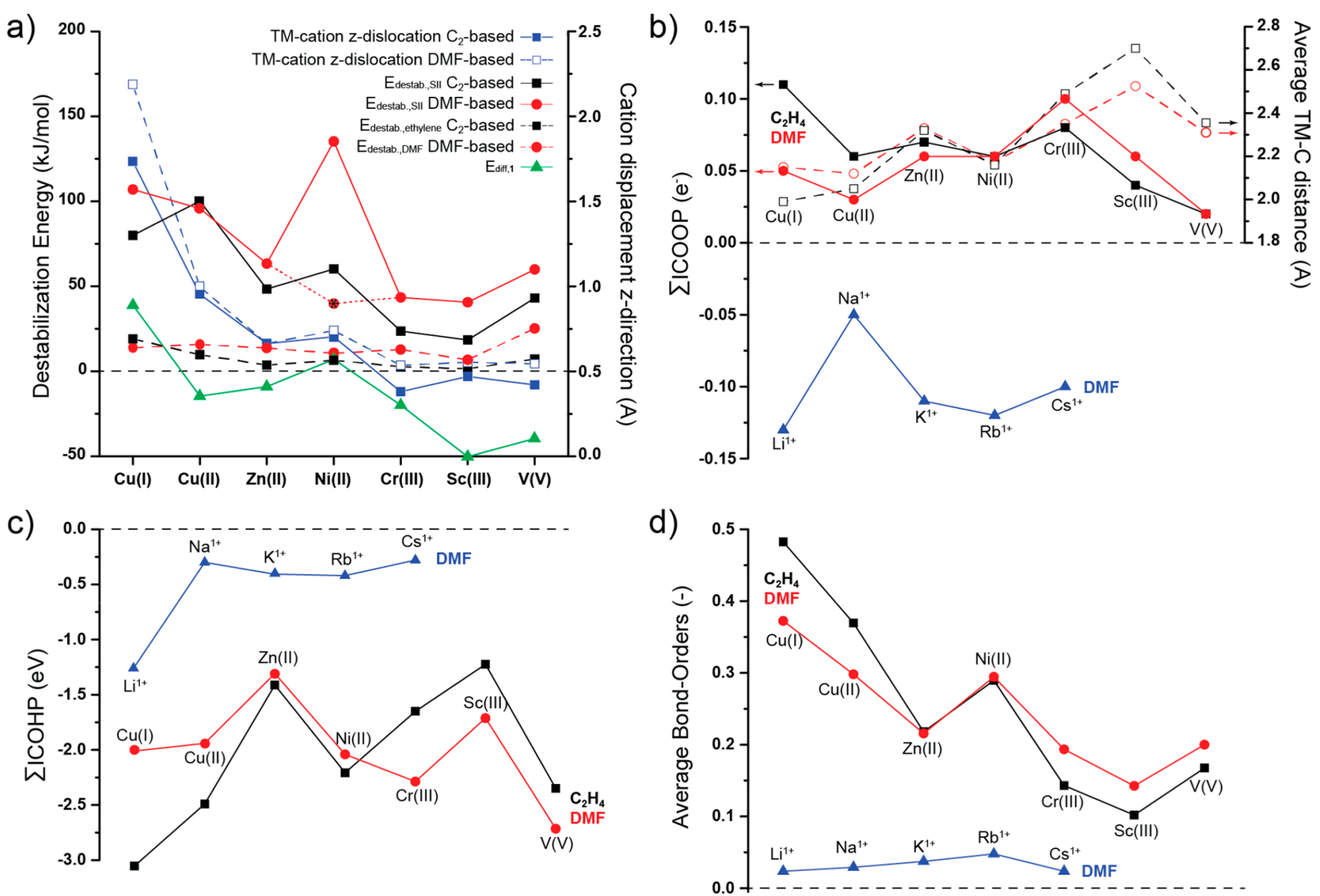

Figure 6. Destabilization energies and TM cation displacements upon $\eta^{2}$-coordination of reactants is shown in (a). The asterisk indicates the destabilization energy caused upon $\eta^{1}$-coordination of DMF to Ni(II). Summed ICOOP-values are shown in (b). The summed ICOHP- and average BO-values are shown in panel $(c)$ and $(d)$, respectively. The primary adsorbent is mentioned next to the plotted lines in panels $(b-d)$.

$\mathrm{Cu}(\mathrm{I})$ is stronger than that of DMF1 with $\mathrm{Cu}(\mathrm{I})$. The high $\mathrm{Cu}(\mathrm{I})$ electron density allows for strong $\pi$-backdonation. Another example is $\mathrm{Cr}(\mathrm{III})$. The open shell $\mathrm{d}^{3}$ configuration allows for both DMF2 coordination via $\mathrm{Cr}(\mathrm{III}) \rightarrow$ DMF2 $\sigma$ acceptor $/ \pi$-donor interactions and DMF1 which exhibits $\mathrm{Cr}(\mathrm{III}) \rightarrow$ DMF1 $\sigma$-donor $/ \pi$-acceptor interactions. Consequently, the $\Delta E_{\text {ads,DMF1-DMF2 }}$ is only $-13 \mathrm{~kJ} / \mathrm{mol}$.

3.2. Reaction Mechanism. The reaction energies of the DAC reaction of DMF1 (henceforth referred to as DMF, unless stated otherwise) with ethylene over high-silica TMexchanged faujasites are displayed in Figure $5 \mathrm{a}-\mathrm{g}$. The solid blue lines represents the reaction energetics of the ethylenebased pathway and solid red those of the DMF-based reaction. In addition, Figure $5 b$ shows the computed net atomic spin density in the DMF-based reaction over Cu(II)FAU. Similar analyses were performed for the ethylene- and DMF-based reactions in $\mathrm{Cu}(\mathrm{II}) \mathrm{FAU}, \mathrm{Cr}(\mathrm{III}) \mathrm{FAU}$, and $\mathrm{Ni}(\mathrm{II}) \mathrm{FAU}$ (Figure S3). Destabilization energies $\left(E_{\text {destab. }}\right)$ of the zeolite and primary adsorbent in the initial state are shown in Figure 6a. This destabilization energy is defined as

$$
E_{\text {destab. }}=E_{\mathbf{1}, X}-E_{X, \text { optimized }}
$$

where $X$ refers to either the TM-exchanged zeolite or one of the reactants taken from state $\mathbf{1}$ and its fully optimized form.

As DMF and ethylene are both $\eta^{2}$-coordinated, the $\mathrm{TM}-\mathrm{C} 5 / \mathrm{TM}-\mathrm{C} 6$ and $\mathrm{TM}-\mathrm{C} 2 / \mathrm{TM}-\mathrm{C} 3$ interactions were quantified by taking the summed ICOOP- and ICOHP-values (Figure $6 \mathrm{~b}$ and Figure $6 \mathrm{c}$, respectively). These results are referenced against similar analysis performed on the previously studied MY. ${ }^{45}$ The average TM-C2/TM-C3 and TM-C5/ TM-C6 bond orders are shown in Figure $6 \mathrm{~d}$ and have been referenced against the average alkali-C2/alkali-C3 or alkali-C5/alkali-C6 bond orders. The net molecular charges of the d-block cations and substrates are listed in Table 2. It is

\section{Table 2. Net Molecular QTAIM-Charges in $1^{a}$}

$\begin{array}{cccccccc} & \mathrm{TM}_{\mathrm{ref}}^{+} & \mathrm{M}^{+} & \underline{\mathrm{C}}_{2} \underline{\mathrm{H}}_{4} & \mathrm{DMF} & \mathrm{M}^{+} & \underline{\mathrm{DMF}} & \mathrm{C}_{2} \mathrm{H}_{4} \\ \mathrm{Cu}(\mathrm{I}) & 0.7 & 0.76 & -0.23 & 0.40 & 0.66 & 0.19 & 0.02 \\ \mathrm{Cu}(\mathrm{II}) & 1.06 & 0.89 & 0.06 & 0.66 & 0.94 & 0.61 & 0.02 \\ \mathrm{Zn}(\mathrm{II}) & 1.34 & 1.26 & 0.14 & 0.12 & 1.27 & 0.23 & 0.02 \\ \mathrm{Ni}(\mathrm{II}) & 1.17 & 1.05 & 0.11 & 0.32 & 1.06 & 0.44 & 0.01 \\ \mathrm{Cr}(\mathrm{III}) & 2.06 & 1.59 & 0.13 & 0.42 & 1.63 & 0.45 & 0.01 \\ \mathrm{Sc}(\mathrm{III}) & 1.86 & 1.82 & 0.11 & 0.07 & 1.81 & 0.27 & 0.00 \\ \mathrm{~V}(\mathrm{~V}) & 1.97 & 1.94 & 0.15 & 0.61 & 1.95 & 0.68 & 0.05\end{array}$

${ }^{a}$ The underlined compound is the primary adsorbent.

noted that one has to be careful in making a direct quantitative comparison of ICOHP-values obtained in different models. ${ }^{95,96}$ It is claimed that this is strictly speaking not possible. However, we find a qualitative ICOHP-trend that corresponds well with the BO-trend. Furthermore, tests indicated that for the evaluated systems in this study, a direct comparison of ICOHP-values is possible. These findings will be reported in due time. 
Initial State Stability. The electronic structure of $\mathbf{1}$ was analyzed to investigate whether the interaction between the active site and reactants was successfully enhanced upon using a d-block cation instead of an alkali cation.

The stability of $\mathbf{1}_{\mathrm{DMF}}$ is generally larger than $\mathbf{1}_{\mathrm{C} 2}$ as apparent from Figure 5 and Figure $6 \mathrm{a}$. In $\mathrm{Cu}$ (II)FAU and $\mathrm{Ni}(\mathrm{II}) \mathrm{FAU}$, there is a preference of 14 and $-7 \mathrm{~kJ} / \mathrm{mol}$ for $\mathbf{1}_{\mathrm{DMF}}$, respectively. For $\mathrm{Cr}(\mathrm{III}) \mathrm{FAU}, \mathrm{Sc}(\mathrm{III}) \mathrm{FAU}$, and $\mathrm{V}(\mathrm{V}) \mathrm{FAU}$, differences of 20,50 , and $40 \mathrm{~kJ} / \mathrm{mol}$ in favor of $\mathbf{1}_{\mathrm{DMF}}$ are found. $\mathrm{Cu}(\mathrm{I}) \mathrm{FAU}$ forms an exception with a $39 \mathrm{~kJ} / \mathrm{mol}$ preference for $\mathbf{1}_{\mathrm{C} 2}$. $\mathrm{Zn}(\mathrm{II}) \mathrm{FAU}$ only shows $9 \mathrm{~kJ} / \mathrm{mol}$ preference for $\mathbf{1}_{\mathrm{DMF}}$ as compared with $\mathbf{1}_{\mathrm{C} 2}$. The primary adsorbents deform slightly upon adsorption, but $E_{\text {destab.,ethylene/DMF }}$ does not exceed $25 \mathrm{~kJ} /$ mol, Figure 6a. Of all the evaluated d-block cations, $\mathrm{Cu}(\mathrm{I})$ and $\mathrm{Cu}$ (II) are pulled out the most of the 6-membered ring upon interacting with the reactants. The result is $\mathrm{Cu}(\mathrm{I}) \mathrm{FAU}$ and $\mathrm{Cu}$ (II)FAU being destabilized the most.

Inspection of Figure $6 \mathrm{~b}$ shows that the summed ICOOPvalues for the reactant $\cdots \mathrm{d}$-block cation interaction are positive (bonding overlap) and increase with concomitant decrease in $\mathrm{d}$-shell filling. This is attributed to the fact that the d-band contributions in the TMFAU DOS get centered more around the Fermi level such that interactions with the reactant HOMO and LUMO are possible. However, $\mathrm{Sc}(\mathrm{III})$ and $\mathrm{V}(\mathrm{V})$ are small cations, and the TM cation...DMF distance is large so that the effective orbital overlap is reduced. Among the evaluated models, $\mathrm{Cu}(\mathrm{I}) \mathrm{FAU}$ has the most bonding interactions (ICOOP $=0.11$ and 0.05 in $\mathbf{1}_{\mathrm{C} 2}$ and $\mathbf{1}_{\mathrm{DMF}}$, respectively) and $\mathrm{V}(\mathrm{V}) \mathrm{FAU}$ the least $\left(\mathrm{ICOOP}=0.03\right.$ and 0.02 for $\mathbf{1}_{\mathrm{C} 2}$ and $\mathbf{1}_{\mathrm{DMF}}$, respectively). ICOOP-values in MY systems are all negative, indicative of antibonding interactions.

A qualitatively similar trend is found with the ICOHPanalysis as compared to the ICOOP-analysis (Figure 6c). Yet, while ICOOP-values for $\mathrm{Sc}(\mathrm{III}) \mathrm{FAU}$ and $\mathrm{V}(\mathrm{V})$ FAU are low, ICOHP-values are high. This is attributed to the large ionic contributions for which the ICOHP-function can partially account. $^{88}$ Of the evaluated MY systems, only LiY shows a relatively high ICOHP-value of ca. $-1.25 \mathrm{eV}$. Relative to the ICOHP-values in the MY and TMFAU models, such an interaction is considered reasonably strong for an MY system. This result, however, is in line with lithium's properties to form covalent bonds with carbon. ${ }^{97}$ The significant difference in ICOHP-values obtained in TMFAU as compared with MY indicate that the increased orbital overlap results in strong bonding to the active site.

For a chemical intuitive interpretation of reactant adsorption onto the active site in the initial state, the DDEC6-derived BO analysis was performed. This shows that $\mathrm{BOs}$ of the TM-C5/ $\mathrm{TM}-\mathrm{C} 6$ and $\mathrm{TM}-\mathrm{C} 2 / \mathrm{TM}-\mathrm{C} 3$ interactions are an order of magnitude larger than those found in the MY models (Figure $6 \mathrm{~d})$. While the bond orders of the alkali-cation $\cdots$ reactant interactions are very close to zero, those of the TM cation... reactant interactions are higher than 0.25 for $\mathrm{Cu}(\mathrm{I})-, \mathrm{Cu}(\mathrm{II})$-, and $\mathrm{Ni}(\mathrm{II}) \mathrm{FAU}$. In $\mathrm{Zn}$ (II)FAU and $\mathrm{Cr}$ (III)FAU slightly lower $\mathrm{TM}-\mathrm{C}$ bond orders are found (i.e., just below 0.25). $\mathrm{Sc}$ (III)FAU shows the lowest bond order. V(V)FAU exhibits a high bond orders as well, attributed to it being a hard Lewis acid ( $\mathrm{d}^{0}$ electron configuration) and the property to form $\mathrm{V}-\mathrm{O}$ and $\mathrm{V}-\mathrm{C}$ covalent bonds.

A summary of the molecular net Bader-charges is found in Table 2. $T M_{\text {ref }}^{+}$refers to the charge of the TM cation in the absence of the reactants. The results show that DMF is always positively charged, irrespective of the primary adsorbent. In the ethylene-based reaction, $q_{\mathrm{DMF}}$ is the largest in $\mathrm{Cu}(\mathrm{II}) \mathrm{FAU}$ $(+0.66)$ and the lowest in Sc(III)FAU $(+0.07)$. In the DMFbased reaction, the molecular DMF net charge is highest in $\mathrm{V}(\mathrm{V})$ FAU $(+0.68)$ and lowest in $\mathrm{Cu}(\mathrm{I})$ FAU $(+0.19)$. An example of a charge difference $(Q)$ visualization concerning $\mathrm{V}(\mathrm{V})$ FAU is shown in Figure $S 4\left(Q=Q_{1}-Q\left(\right.\right.$ TMFAU $\left._{1}\right)-$ $\left.Q\left(\mathrm{C}_{2} \mathrm{H}_{4,1}\right)-Q\left(\mathrm{DMF}_{1}\right)\right)$ and indicates that charge is transferred to the TM cation and the zeolite framework. The charging of DMF is in line with earlier observed electron transfer between furanic compounds in TM-exchanged zeolites. $^{98}$

Summarizing, transition metal-reactant orbital interactions are of bonding nature, while the alkali metal-reactant orbital interactions are of antibonding nature. In contrast to MY, ICOHP-values are 2-6 times higher and BOs are an order of magnitude larger in TMFAU. The strength of the TM cation $\cdots$ reactant interactions qualitatively follows the expected degrees of the TM cation $\sigma$-donor/acceptor and $\pi$-donor/acceptor properties.

DAC Reaction. The efficient orbital interactions between the TM cation and DAC reactants identified above may give rise to substantial charge redistributions in the reactive ensemble. However, our calculations reveal significant electron transfer between the reactants and the zeolite site only for the $\mathrm{Cu}(\mathrm{II}) \mathrm{FAU}$ system (Figure $5 \mathrm{~b}$ and Figure S3). The largest accumulation of the spin on DMF is found in the DMF-based reaction over $\mathrm{Cu}(\mathrm{II}) \mathrm{FAU}$ with a value of 0.73 on the $\mathrm{C} 5$ atom in $\mathbf{I}_{\mathrm{DMF}}$. This implies that the DMF adsorption is accompanied by the (partial) reduction of the copper center to an effective $\mathrm{Cu}(\mathrm{I})$ state. In the course of the reaction, the oxidation state of the TM center is restored. The value of spin on C5 reduces to 0.27 in TS2 $_{\mathrm{DMF}}$. For the ethylene-based reaction over $\mathrm{Cu}(\mathrm{II}) \mathrm{FAU}$, the adsorption-induced active site reduction is less pronounced. The $\eta^{1}$-coordination of $\mathrm{C}_{2} \mathrm{H}_{4}(\mathrm{Cu}(\mathrm{II})-\mathrm{C} 5)$ with the paramagnetic active site gives rise to a spin-moment of only 0.22 on C6. No substantial adsorption-induced reduction is observed for other open shell TM cations such as $\mathrm{Cr}$ (III) and $\mathrm{Ni}(\mathrm{II})$. Spin-moments on the organic molecules in the adsorption complexes do not exceed an absolute value of 0.15 . The reduction of $\mathrm{Cu}$ (II) and the invariable spin density on $\mathrm{Cr}$ (III) were also found experimentally in $\mathrm{Cu}(\mathrm{II})$ - and $\mathrm{Cr}$ (III)exchanged clay-based DAC-catalysts. ${ }^{52}$

The coupling in all other systems can be described as proceeding via a zwitterionic intermediate, although charge changes are small $(|\Delta q| \approx 0.1)$. In the C2-based reaction following the two-step pathway, electron density accumulates on the carbon atom bound to the TM cation $\left(\mathrm{C}_{\mathrm{TM}}\right)$ when going from $\mathbf{1}_{\mathrm{C} 2}$ to $\mathrm{I}_{\mathrm{C} 2}$. Meanwhile, the terminal carbon atom in the $\mathrm{C} 2$-moiety is characterized by a reduction in electron density. Additionally, the carbon atom in DMF and opposite to $\mathrm{C}_{\mathrm{TM}}$ in $\mathrm{I}_{\mathrm{C} 2}$ is characterized by an increase net positive charge as compared to the $\mathrm{C}_{\mathrm{DMF}^{-}}$atom that has already participated in the first $\mathrm{C}-\mathrm{C}$ bond formation. For the DMF-based reaction following the two-step pathway, an electron density increase was observed on the terminal $\mathrm{C}$ atom of the $\mathrm{C} 2$-moiety with the opposite $\mathrm{C}_{\mathrm{DMF}}$-atom having an increased net positive charge. In both the C2- and DMF-based reactions, the combination of the net positive and net negative charge is considered to be the driving force for the formation of the second $\mathrm{C}-\mathrm{C}$ bond.

Next we analyze more specifically the orbital interactions within each of the reactive systems and the changes in the bonding patterns during the DAC reaction. The bond orders 
a)

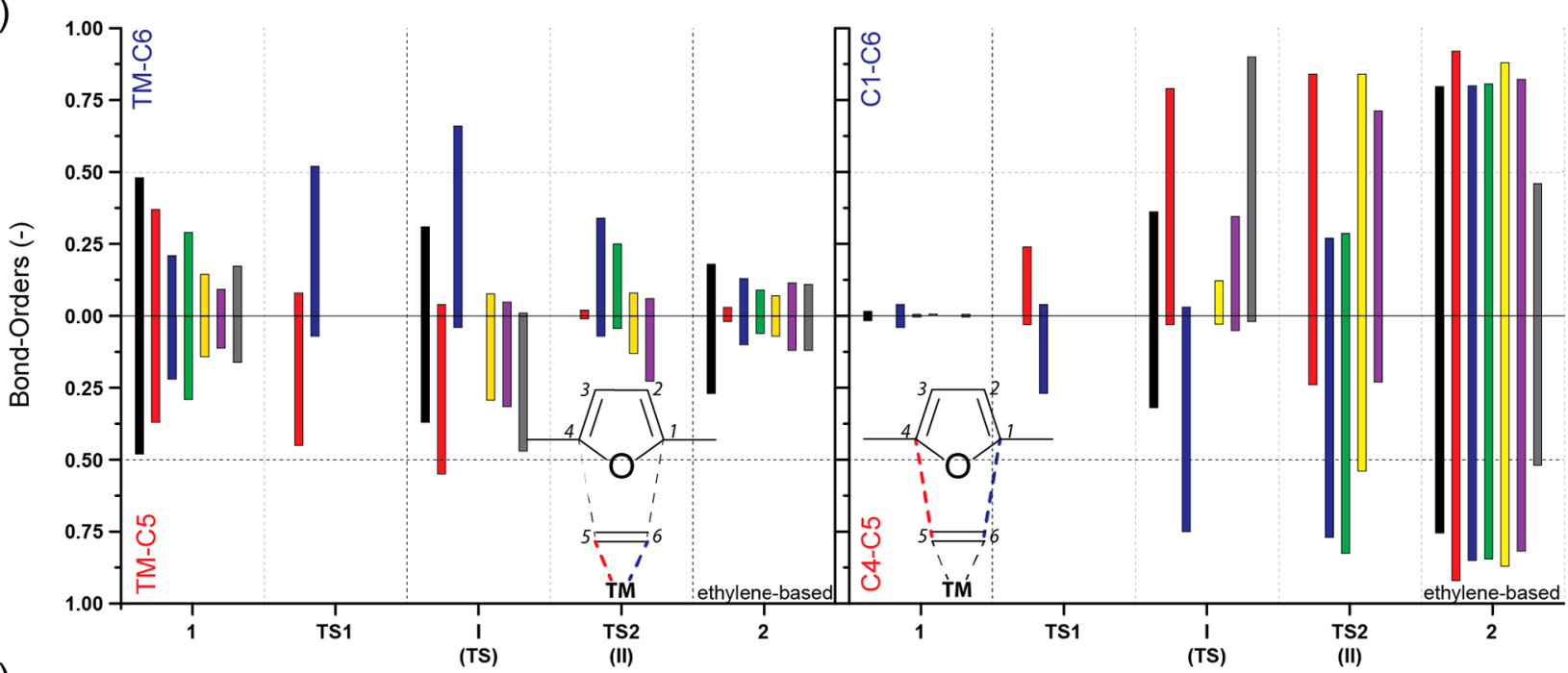

b)

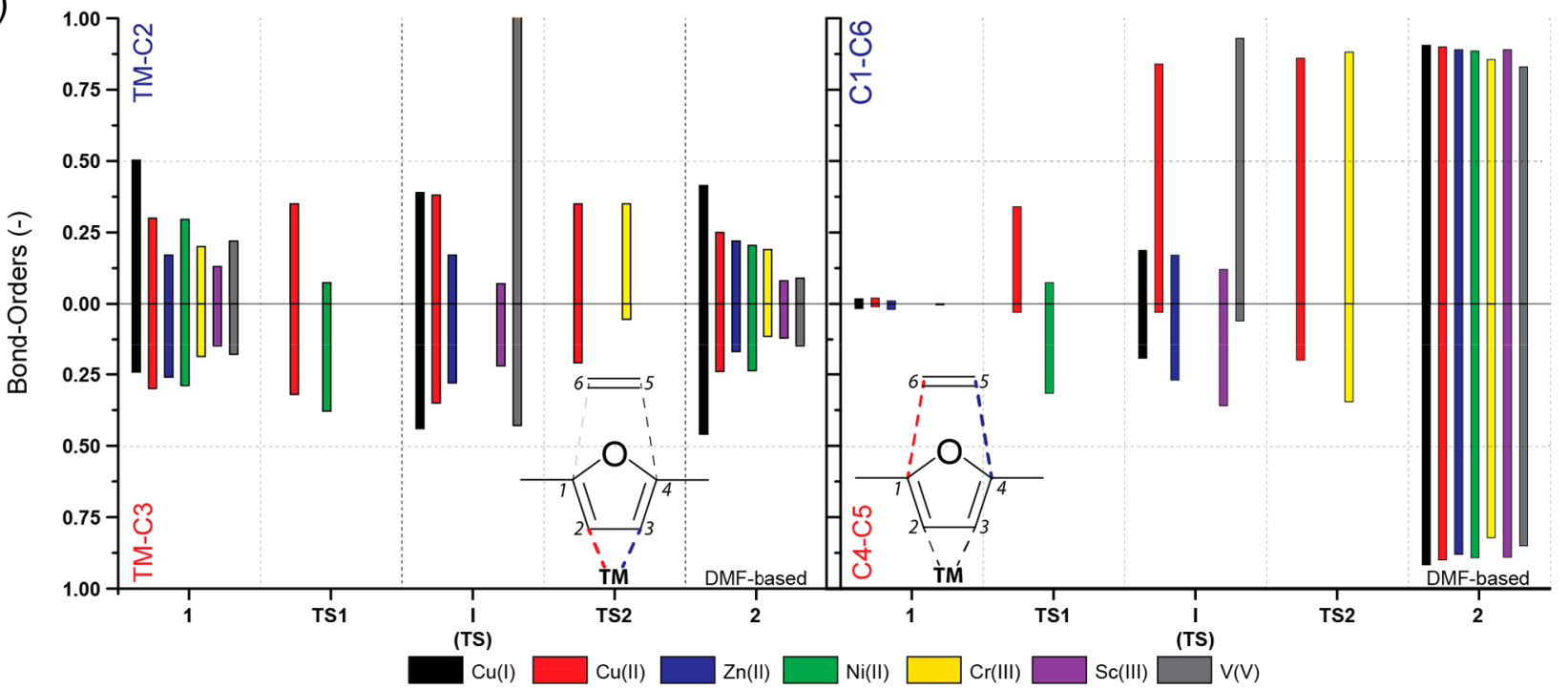

Figure 7. Barplots of TM-C and $\mathrm{C}-\mathrm{C}$ bond orders along the reaction coordinate for the various d-block cations in the ethylene- and DMF-based pathways. Bonds of interest are highlighted in red or blue. Note that these colors have no relation with the colors in the legend and the bars. They only refer to the accompanying text in the graph.

between the TM cation and the primary adsorbents along the reaction coordinate (r.c.) are reported in Figure 7, Table S1, and Table S2. Bond orders are typically referred to interacting pairs in the text (e.g., TM-C2/TM-C3 and $\mathrm{C} 1-\mathrm{C} 6$ / C4-C5). In the following, we first conduct a detailed analysis per model and then close with a summary describing the trends. Note that we always refer to DMF1 when mentioning DMF as primary adsorbent. All the obtained geometries over all evaluated TMFAU catalysts can be found in Figures S5-S7.

CU(I)FAU. The relative stabilities (defined as the coadsorption energies) of $\mathbf{1}_{\mathrm{C} 2}$ and $\mathbf{1}_{\mathrm{DMF}}$ are -189 and $-150 \mathrm{~kJ} /$ mol, respectively (Figure 5 ). The activation barriers $E_{\text {act, } 1 \rightarrow \mathrm{TS}, \mathrm{C} 2}$ and $E_{\text {act, } 1 \rightarrow \mathrm{TS}, \mathrm{DMF}}$ are 144 and $54 \mathrm{~kJ} / \mathrm{mol}$, respectively. Overall, the ethylene-based reaction is endothermic with $116 \mathrm{~kJ} / \mathrm{mol}$ and the DMF-based reaction is exothermic with $76 \mathrm{~kJ} / \mathrm{mol}$.

The $4 \mathrm{~s}$ and $3 \mathrm{~d}$-orbitals of $\mathrm{Cu}(\mathrm{I})$ are close to the Fermi level (Figure 4). In Figure 3, it is seen that the d-orbitals and the 4sorbital are at the same energy level as the ethylene HOMO. Because the d-shell is completely filled, we believe that it is predominantly the $4 \mathrm{~s}$-shell that accepts the electrons from ethylene via ethylene $\rightarrow \mathrm{Cu}(\mathrm{I}) \sigma$-donation. The ethylene
LUMO interacts with a band originating from d-orbitals. Consequently, the $\eta^{2}$-coordination of ethylene to the $\mathrm{Cu}(\mathrm{I})$ cation results in a $e_{\text {norm, C2 }}$ and $e_{\text {inv, C2 }}$ of 2.69 and $5.56 \mathrm{eV}$, respectively. The $\eta^{2}$-coordination of $\mathrm{DMF}$ to $\mathrm{Cu}(\mathrm{I})$ in the DMF-based reaction results in the HOMO of DMF having the same energy as a d-band from $\mathrm{Cu}(\mathrm{I})$ and a contribution of the $\mathrm{Cu}(\mathrm{I}) 4 \mathrm{~s}$ orbital at the DMF LUMO. The result is an $e_{\text {norm,DMF }}$ of $4.31 \mathrm{eV}$ and an $e_{\text {inv, DMF }}$ of $4.6 \mathrm{eV}$.

During the reaction, $\mathrm{Cu}(\mathrm{I})-\mathrm{C} 5 / \mathrm{Cu}(\mathrm{I})-\mathrm{C} 6$ bond orders in the ethylene-based reaction change from $0.48 / 0.48$ in $\mathbf{1}_{\mathrm{C} 2}$ to $0.27 / 0.18$ in $\mathbf{2}_{\mathrm{C} 2}$, Figure 7 . In $\mathbf{T S}_{\mathrm{C} 2}$, the bond orders are $0.37 /$ 0.31 . Accordingly, $\mathrm{C} 1-\mathrm{C} 6 / \mathrm{C} 4-\mathrm{C} 5$ bond orders change from 0 in $\mathbf{1}_{\mathrm{C} 2}$ to $0.8 / 0.76$ in $\mathbf{2}_{\mathrm{C} 2}$ with BOs of $0.36 / 0.32$ in $\mathbf{T S}_{\mathrm{C} 2}$. In the case of the DMF-based reaction, the TM-C2/TM-C3 BOs are $0.5 / 0.24$ in $\mathbf{1}_{\mathrm{DMF}}$ and increase to $0.41 / 0.56$ in $\mathbf{2}_{\mathrm{DMF}}$. Bond order values of $\mathrm{Cu}(\mathrm{I})-\mathrm{C} 2 / \mathrm{Cu}(\mathrm{I})-\mathrm{C} 3$ in $\mathrm{TS}_{\mathrm{DMF}}$ are $0.39 / 0.44$. Along the reaction coordinate, the $\mathrm{C} 1-\mathrm{C} 6 / \mathrm{C} 4-\mathrm{C} 5$ BOs change from $0.01 / 0.01$ to $019 / 0.19$ and $0.92 / 0.91$ in $\mathbf{1}_{\mathrm{DMF}}, \mathbf{T S}_{\mathrm{DMF}}$, and $\mathbf{2}_{\mathrm{DMF}}$ respectively.

$\mathrm{CU}(\mathrm{II}) F A U$. The DAC reactions over $\mathrm{Cu}$ (II)FAU start from initial states $\mathbf{1}_{\mathrm{C} 2}$ and $\mathbf{1}_{\mathrm{DMF}}$ with energies of -173 and $-187 \mathrm{~kJ} /$ 
mol, respectively (Figure 5). Upon $\eta^{2}$-coordination of ethylene to $\mathrm{Cu}(\mathrm{II})$, contributions of both the $\mathrm{Cu}$ (II) d-orbitals and the HOMO and LUMO of ethylene to the same band are observed, Figure 3. Ethylene $\rightarrow \mathrm{Cu}$ (II) $\sigma$-donation and $\mathrm{Cu}(\mathrm{II})$ $\rightarrow$ ethylene $\pi$-backbonding are possible due to the $\mathrm{d}^{9}$ electron configuration of $\mathrm{Cu}(\mathrm{II})$. Qualitatively similar results are found for the DMF-based reaction, where the $\mathrm{Cu}$ (II) d-orbitals and HOMO/LUMO contribute to the same bands, enabling $\mathrm{Cu}(\mathrm{II}) \rightarrow$ DMF $\sigma$-donation and DMF $\rightarrow \mathrm{Cu}(\mathrm{II}) \pi$-donation. The $e_{\text {norm }}\left(e_{\text {inv }}\right)$ for the ethylene- and DMF-based reactions are $4.03(0.64) \mathrm{eV}$ and $1.06(5.28) \mathrm{eV}$, respectively.

The $E_{\mathrm{act}, 1 \rightarrow \mathrm{TS} 1, \mathrm{C} 2}$ and $E_{\mathrm{act}, 1 \rightarrow \mathrm{TS} 1, \mathrm{DMF}}$ amount to 30 and $54 \mathrm{~kJ} /$ mol, respectively. Those of $E_{\mathrm{act}, \mathrm{I} \rightarrow \mathrm{TS} 2, \mathrm{C} 2}$ and $E_{\mathrm{act}, \mathrm{I} \rightarrow \mathrm{TS} 2, \mathrm{DMF}}$ are 92 and $17 \mathrm{~kJ} / \mathrm{mol}$, respectively. It should be noted that in $\mathbf{I}_{\mathrm{C} 2}$ the maximum spin density is found to be 0.22 , whereas that of $\mathbf{I}_{\mathrm{DMF}}$ is 0.73 . So, in the latter situation there is a large driving force for the second $\mathrm{C}-\mathrm{C}$ coupling as compared with the first case. Upon formation of a net spin moment on the carbon atoms, $\mathrm{Cu}(\mathrm{II})$ is reduced due to reduction potential favoring this process, ${ }^{99}$ in line with earlier experimental observations. ${ }^{52}$ The overall reaction is endothermic for both the ethylene- and DMF-based reaction with 66 and $37 \mathrm{~kJ} / \mathrm{mol}$. However, the second step is most endothermic for the ethylene-based reaction $(59 \mathrm{~kJ} / \mathrm{mol})$, while the first step is most endothermic for the DMF-based reaction $(36 \mathrm{~kJ} / \mathrm{mol})$.

$\mathrm{Cu}(\mathrm{II})-\mathrm{C}$ bond orders for $\mathrm{Cu}(\mathrm{II})-\mathrm{C} 5 / \mathrm{Cu}(\mathrm{II})-\mathrm{C} 6$ are $0.37 / 0.37$ in $\mathbf{1}_{\mathrm{C} 2}$, but they decrease to an insignificant 0.03 / 0.02 in $\mathbf{2}_{\mathrm{C} 2}$, Figure 7 . The intermediate state $\mathbf{1}_{\mathrm{C} 2}$ exhibits $\mathrm{Cu}(\mathrm{II})-\mathrm{C} 5 / \mathrm{Cu}(\mathrm{II})-\mathrm{C} 6(\mathrm{C} 1-\mathrm{C} 6 / \mathrm{C} 4-\mathrm{C} 5)$ BOs of $0.55 / 0.04$ $(0.79 / 0.03)$ indicating a $\eta^{1}$-coordinated ethylene with a net spin density on $\mathrm{C} 5$ of 0.22 . For the DMF-based reaction, $\mathrm{Cu}(\mathrm{II})-\mathrm{C} 2 / \mathrm{Cu}(\mathrm{II})-\mathrm{C} 3 \mathrm{BOs}$ change from $0.3 / 0.3$ in $\mathbf{1}_{\mathrm{DMF}}$ to $0.25 / 0.24$ in $2_{\mathrm{DMF}}$. Although a significant spin moment has developed on the $\mathrm{C} 6$ atom $(0.73)$ in $\mathrm{I}_{\mathrm{DMF}}$, the $\mathrm{Cu}(\mathrm{II})-\mathrm{C} 2$ / $\mathrm{Cu}(\mathrm{II})-\mathrm{C} 3 \mathrm{BOs}$ remain relatively modest as compared with the ethylene-based reaction with $0.38 / 0.35$. Yet, the $\mathrm{C} 1-\mathrm{C} 6$ bond is well-developed in $\mathrm{I}_{\mathrm{DMF}}$ as indicated by a $\mathrm{BO}$ of 0.84 . In $\mathbf{2}_{\mathrm{DMF}}$, both $\mathrm{C}-\mathrm{C}$ bonds will have a $\mathrm{BO}$ of 0.9 in $\mathbf{2}_{\mathrm{DMF}}$.

$\mathrm{Zn}(\mathrm{II}) F A U$. The stabilities of both $\mathbf{1}_{\mathrm{C} 2} / \mathrm{Zn}$ (II)FAU and $\mathbf{1}_{\mathrm{DMF}} / \mathrm{Zn}$ (II)FAU are very similar to those found in $\mathbf{1}$ / $\mathrm{Cu}(\mathrm{I}) \mathrm{FAU}$, Figure 5. For the ethylene- and DMF-based reactions the energies of 1 are -151 and $-160 \mathrm{~kJ} / \mathrm{mol}$, respectively. The $\mathrm{Zn}(\mathrm{II})$ reference DOS (Figure 4) and the pDOS of the ethylene- and DMF-based initial states (Figure 3) show that the d-orbitals are too low in energy to play a significant role. From this we infer that the major orbital interaction between ethylene and $\mathrm{Zn}$ (II) arises from the $\mathrm{Zn}$ (II) s-orbital with the HOMO and LUMO of ethylene. A similar observation is done for the DMF-based reaction. The interaction with $\mathrm{Zn}(\mathrm{II})$ results in an $e_{\mathrm{norm}, \mathrm{C} 2}\left(e_{\mathrm{inv}, \mathrm{C} 2}\right)$ of 2.6 (2.59) $\mathrm{eV}$ and $e_{\text {norm,DMF }}\left(e_{\text {inv,DMF }}\right)$ of $5.24(4.01) \mathrm{eV}$ for the C2and DMF-based reaction, respectively.

$\mathrm{Zn}(\mathrm{II})-\mathrm{C}$ bond orders in $\mathbf{I}_{\mathrm{C} 2}$ are high with values for $\mathrm{Zn}(\mathrm{II})-\mathrm{C} 2 / \mathrm{Zn}(\mathrm{II})-\mathrm{C} 3$ of $0.66 / 0.04$, Figure 7 . The overall reaction is endothermic with $24 \mathrm{~kJ} / \mathrm{mol}$ while formation of $\mathbf{I}_{\mathrm{C} 2}$ is an exothermic process with a $\Delta E$ of $5 \mathrm{~kJ} / \mathrm{mol}$. The DMFbased reaction is exothermic with $30 \mathrm{~kJ} / \mathrm{mol}$.

The $\mathrm{Zn}(\mathrm{II}) \rightarrow$ DMF $\sigma$-donation and $\mathrm{DMF} \rightarrow \mathrm{Zn}(\mathrm{II}) \pi$ donation both deal with an empty $\mathrm{Zn}$ (II) 4s-shell. In combination with steric hindrance from the framework, the DMF-based reaction proceeds via a one-step pathway which is overall exothermic with $30 \mathrm{~kJ} / \mathrm{mol}$. The barrier, however, is relatively high with $65 \mathrm{~kJ} / \mathrm{mol}$.
For ethylene, the $\mathrm{Zn}(\mathrm{II})-\mathrm{C} 5 / \mathrm{Zn}(\mathrm{II})-\mathrm{C} 6$ bond orders change from $0.21 / 0.22$ in $\mathbf{1}_{\mathrm{C} 2}$ to $0.10 / 0.13$ in $2_{\mathrm{C} 2}$, Figure 7 . In $I_{C 2}$, these values have become $0.04 / 0.66$ and are accompanied by $\mathrm{C} 1-\mathrm{C} 6 / \mathrm{C} 4-\mathrm{C} 5 \mathrm{BOs}$ of $0.03 / 0.75$. In $\mathbf{2}_{\mathrm{C} 2}$ the $\mathrm{C} 1-\mathrm{C} 6 / \mathrm{C} 4-\mathrm{C} 5 \mathrm{BOs}$ are $0.80 / 0.85$. During the DMFbased reaction involving the one-step pathway, the DMFmoiety remains $\eta^{2}$-coordinated as evidenced by $\mathbf{T S}_{\mathrm{DMF}}$ $\mathrm{Zn}(\mathrm{II})-\mathrm{C} 2 / \mathrm{Zn}(\mathrm{II})-\mathrm{C} 3 \quad \mathrm{BOs}$ of $0.17 / 0.28$. The $\mathrm{C} 1-\mathrm{C} 6 /$ C4-C5 BOs are relatively low as compared to the ethylenebased pathway with just $0.17 / 0.27$, but they evolve to $\mathrm{C} 1-\mathrm{C} 6$ / C4-C5 bonds with BOs of $0.88 / 0.89$.

Ni(II)FAU. The Ni(II) DOS exhibits d-bands just above and below the Fermi level, Figure 4. This allows for proper ethylene $\rightarrow \mathrm{Ni}(\mathrm{II}) \sigma$-donation and $\mathrm{Ni}(\mathrm{II}) \rightarrow$ ethylene $\pi$ backbonding and $\mathrm{Ni}(\mathrm{II}) \rightarrow$ DMF $\sigma$-donation and DMF $\rightarrow$ $\mathrm{Ni}$ (II) $\pi$-donation. The resulting initial states $\mathbf{1}_{\mathrm{C} 2}$ and $\mathbf{1}_{\mathrm{DMF}}$ are -163 and $-156 \mathrm{~kJ} / \mathrm{mol}$ lower in energy than in the situation of all components in the gas phase, respectively (Figure 5). Energy gaps are 0.4 and $0.59 \mathrm{eV}$ for $e_{\text {norm }}$ and $e_{\text {inv }}$ in the ethylene-based reaction, respectively. Formation of the reactive complex is easy as both the ethylene and DMF DOS display bands at the Fermi level, Figure 3. For the DMF-based reaction, $e_{\text {norm }}$ and $e_{\text {inv }}$ are 5.24 and $1.16 \mathrm{eV}$, respectively.

The ethylene-based reaction is an endothermic reaction of $38 \mathrm{~kJ} / \mathrm{mol}$. An equilibrium is established between $\mathbf{T S} \boldsymbol{2}_{\mathrm{C} 2}$ and $\mathbf{2}_{\mathrm{C} 2}$ indicating that the retro-DAC can take place easily. We note that the energy difference between these two states is only $1 \mathrm{~kJ} / \mathrm{mol}$, and given the flexibility of the current zeolite models and its complexity, it can be regarded as being within the error margin of our DFT calculations. The DMF-based pathway is characterized by a low first activation barrier of just $29 \mathrm{~kJ} / \mathrm{mol}$. The overall reaction is exothermic and state $2_{\mathrm{DMF}}$ is $52 \mathrm{~kJ} / \mathrm{mol}$ lower in energy. The retro-DAC cannot take place as easily as in the case of the ethylene-based reaction as the retro-DAC activation barrier is $81 \mathrm{~kJ} / \mathrm{mol}$. For both the ethylene- and DMF-based reactions, net spin moments were found to be not larger than 0.1 (only once, for one atom, a net spin density of 0.13 is found), Figure S3. No significant spin changes on the $\mathrm{Ni}(\mathrm{II})$ active site were observed.

The TM-C bond orders for both the $\mathrm{C}_{2}$ - and DMF-based reactions were found to be nearly as large as those found in $\mathbf{1}$ / $\mathrm{Cu}(\mathrm{II}) \mathrm{FAU}$, Figure 7. All $\mathrm{BO}$ values were ca. 0.29. In the ethylene-based reaction, TM-C bond orders change to 0.04/ 0.25 for $\mathrm{Ni}(\mathrm{II})-\mathrm{C} 5 / \mathrm{Ni}(\mathrm{II})-\mathrm{C} 6$ in $\mathbf{T S} 2_{\mathrm{C} 2}$ and eventually to $0.06 / 0.09$ in $2_{\mathrm{C} 2}$. The $\mathrm{C} 1-\mathrm{C} 6 / \mathrm{C} 4-\mathrm{C} 5 \mathrm{BOs}$ are $0.29 / 0.83$ in TS2 ${ }_{\mathrm{C} 2}$ and continue to increase to $0.81 / 0.85$ in $\mathbf{2}_{\mathrm{C} 2}$. For the DMF-based reaction, $\mathrm{Ni}(\mathrm{II})-\mathrm{C} 2 / \mathrm{Ni}(\mathrm{II})-\mathrm{C} 3$ bond orders go from $0.07 / 0.38$ in $\mathbf{T S}_{\mathrm{DMF}}$ to $0.21 / 0.24$ in $\mathbf{2}_{\mathrm{DMF}}$. A concomitant change in $\mathrm{C} 1-\mathrm{C} 6 / \mathrm{C} 4-\mathrm{C} 5$ bond orders is found, from $0.07 / 0.32$ in $\mathbf{T S} 1_{\mathrm{DMF}}$ to $0.99 / 0.99$ in $\mathbf{2}_{\mathrm{DMF}}$.

$\mathrm{Cr}(I I I) F A U$. The DOS of $\mathrm{Cr}$ (III)FAU without substrates exhibits d-bands below, nearly at and above the Fermi level, Figure 4. This is expected to allow for significant ethylene $\rightarrow$ $\mathrm{Cr}$ (III) $\sigma$-donation and $\mathrm{Cr}$ (III) $\rightarrow$ ethylene $\pi$-backbonding and $\mathrm{Cr}(\mathrm{III}) \rightarrow$ DMF $\sigma$-donation and $\mathrm{DMF} \rightarrow \mathrm{Cr}(\mathrm{III}) \pi$ donation. The resulting energy gaps are $0.4 \mathrm{eV}(5.48 \mathrm{eV})$ and $0.6 \mathrm{eV}(0.53 \mathrm{eV})$ for the normal and inverse electron mechanisms in the ethylene-(DMF-)based reaction, respectively, as deduced from the DOS in Figure 3. The orbital interactions between $\mathrm{Cr}(\mathrm{III})$ and the reactants are significant. Additionally, as an electrophile, $\mathrm{Cr}$ (III) polarizes the reactants. The result is state $\mathbf{1}_{\mathrm{C} 2}$ and $\mathbf{1}_{\mathrm{DMF}}$ of -200 and $-220 \mathrm{~kJ} / \mathrm{mol}$, respectively, Figure 5. Formation of the intermediate state $\mathbf{I}_{\mathrm{C} 2}$ 
for the ethylene-based pathway occurs without barrier and is exothermic with $47 \mathrm{~kJ} / \mathrm{mol}$. The second coupling step $\mathbf{I}_{\mathrm{C} 2} \rightarrow$ $\mathbf{2}_{\mathrm{C} 2}$ is endothermic by $116 \mathrm{~kJ} / \mathrm{mol}$ and proceeds without a barrier. An additional intermediate II was located along the reaction path that precedes $\mathbf{2}_{\mathrm{C} 2}$. No transition state between $\mathrm{I}_{\mathrm{C} 2}$ and II was found, from which we infer that the loss of the $\mathrm{Cr}$ (III)-substrate interaction partially accounts for the energy required to form the second $\mathrm{C}-\mathrm{C}$ bond. The cleavage of the $\mathrm{Cr}(\mathrm{III})-\mathrm{C}$ bond in II and the formation of the reaction $2_{\mathrm{C} 2}$ is slightly endothermic with $\Delta E_{\mathrm{II} \rightarrow 2_{\mathrm{C} 2}}=8 \mathrm{~kJ} / \mathrm{mol}$. Thus, the retroDAC can happen easily, just like the ethylene-based reaction over $\mathrm{Ni}(\mathrm{II}) \mathrm{FAU}$. The DMF-based reaction result in the formation of the DAC adduct $\mathbf{2}_{\mathrm{DMF}}(-222 \mathrm{~kJ} / \mathrm{mol})$ after a barrier of $43 \mathrm{~kJ} / \mathrm{mol}$ has been crossed. During the reaction, net atomic spin moments do not exceed an absolute value of 0.15 . The largest spin moment is located at the DMF methyl side groups in $\mathbf{1}_{\mathrm{C} 2}$, Figure S3. $\mathrm{Cr}(\mathrm{III})$ is not undergoing spin changes, nor does it accept electron density from any of the adsorbents. This is in line with earlier work on $\mathrm{Cr}$ (III)exchanged clays. ${ }^{52}$

The changes in bond orders can be found in Figure 7. The bond orders of the $\mathrm{Cr}(\mathrm{III})-\mathrm{C} 5 / \mathrm{Cr}$ (III) $-\mathrm{C} 6$ interactions are $0.14 / 0.14$ in $1_{\mathrm{C} 2}$ and those of $\mathrm{Cr}(\mathrm{III})-\mathrm{C} 2 / \mathrm{Cr}(\mathrm{III})-\mathrm{C} 3$ are $0.19 / 0.2$ in $\mathbf{1}_{\mathrm{DMF}}$. Formation of state $\mathbf{I}_{\mathrm{C} 2}$ is accompanied by $\mathrm{Cr}(\mathrm{III})-\mathrm{C} 5 / \mathrm{Cr}$ (III)-C6 BOs of $0.29 / 0.08$, which gradually evolve to $0.07 / 0.07$ in $\mathbf{2}_{\mathrm{C} 2}$ via values of $0.13 / 0.08$ in $\mathbf{T S} 2_{\mathrm{C} 2}$. $\mathrm{C} 1-\mathrm{C} 6 / \mathrm{C} 4-\mathrm{C} 5$ bond orders in $\mathrm{I}_{\mathrm{C} 2}$ are small and only 0.12 / 0.03 . They become relatively developed in II with values of $0.84 / 0.54$. In $2_{\mathrm{C} 2}, \mathrm{C} 1-\mathrm{C} 6 / \mathrm{C} 4-\mathrm{C} 5 \mathrm{BOs}$ are $0.88 / 0.87$. For $\mathrm{DMF}$, the $\mathrm{Cr}(\mathrm{III})-\mathrm{C} 2 / \mathrm{Cr}(\mathrm{III})-\mathrm{C} 3$ bond orders become $0.35 / 0.06$ in TS2 $_{\mathrm{DMF}}$ and eventually become $0.19 / 0.11$ in $\mathbf{2}_{\mathrm{DMF}}$. The $\mathrm{C} 1-\mathrm{C} 6 / \mathrm{C} 4-\mathrm{C} 5$ bond orders are $0.88 / 0.35$ in TS $2_{\text {DMF }}$ and eventually $0.86 / 0.82$ in $\mathbf{2}_{\mathrm{DMF}}$.

SC(III)FAU. The reference DOS of Sc(III)FAU shows major $3 \mathrm{~d}$-contributions at $2 \mathrm{eV}$ and higher above the Fermi level, Figure 4. A contribution of the 4 s orbital is also found near 2 $\mathrm{eV}$. Only minor d-orbital contributions are found below the Fermi level. Thus, only ethylene $\rightarrow \mathrm{Sc}$ (III) and $\sigma$-donation $\mathrm{DMF} \rightarrow \mathrm{Sc}$ (III) $\pi$-donation are possible, in conjunction with strong ionic interactions with the highly Lewis acidic Sc(III) cation. The normal and inverse electron demand energy gaps of the ethylene-based reaction are both $0.65 \mathrm{eV}$. Those of the DMF-based reaction are 5.93 and $2.52 \mathrm{eV}$, respectively.

The C2-based reaction starts with the primary adsorption of ethylene resulting in the state $\mathbf{1}_{\mathrm{C} 2}$ with an energy of $-160 \mathrm{~kJ} /$ mol, Figure 5. It proceeds to $\mathbf{I}_{\mathrm{C} 2}$, which is uphill with $13 \mathrm{~kJ} /$ mol. The second activation barrier is $22 \mathrm{~kJ} / \mathrm{mol}$ after which $\mathbf{2}_{\mathrm{C} 2}$ is reached $(-156 \mathrm{~kJ} / \mathrm{mol})$. The DMF-based reaction proceeds via an asynchronous concerted transition state $\left(\mathrm{TS}_{\mathrm{DMF}},-128\right.$ $\mathrm{kJ} / \mathrm{mol}$ ) with a barrier of $82 \mathrm{~kJ} / \mathrm{mol}$. The final state $\mathbf{2}_{\mathrm{DMF}}$ is similar in energy to the initial state.

Inspection of Figure 7 shows that the $\mathrm{Sc}(\mathrm{III})-\mathrm{C} 5 /$ $\mathrm{Sc}(\mathrm{III})-\mathrm{C} 6$ bond orders are only $0.11 / 0.09$ in $\mathbf{1}_{\mathrm{C} 2}, 0.32 / 0.05$ in $\mathbf{I}_{\mathrm{C} 2}$ and $0.23 / 0.06$ in $\mathbf{T S} \mathbf{2}_{\mathrm{C} 2}$. The bond orders restore to the initial values in $2_{\mathrm{C} 2}$, with $0.12 / 0.12$. The $\mathrm{C} 1-\mathrm{C} 6 / \mathrm{C} 4-\mathrm{C} 5$ carbon-carbon bonds are $0.35 / 0.05$ in $\mathrm{I}_{\mathrm{C} 2}$. These C1-C6/ C4-C5 bonds eventually reach values of $0.82 / 0.82$ in $2_{\mathrm{C} 2}$ via $\mathrm{TS}_{\mathrm{C} 2}$ characterized by BOs of $0.71 / 0.23$ for $\mathrm{C} 1-\mathrm{C} 6 / \mathrm{C} 4-\mathrm{C} 5$. For the DMF-based reaction, $\mathrm{Sc}(\mathrm{III})-\mathrm{C} 2 / \mathrm{Sc}(\mathrm{III})-\mathrm{C} 3$ bond orders change from $0.15 / 0.13$ in $\mathbf{1}_{\mathrm{DMF}}$ to $0.12 / 0.08$ in $\mathbf{2}_{\mathrm{DMF}}$ via values of $0.22 / 0.07$ in TS2 $2_{\mathrm{DMF}}$. Bond order values of $\mathrm{C} 1-\mathrm{C} 6 /$ C4-C5 are $0.12 / 0.36$ in $\mathbf{T S}_{\mathrm{DMF}}$ and reach $0.89 / 0.89$ in $\mathbf{2}_{\mathrm{DMF}}$.
V(V)FAU. Analysis of Figure 4 shows that the d-DOS exhibits peaks at and just above the Fermi level. There is also a relatively small contribution of the 4s-orbital at the Fermi level. As $\mathrm{V}(\mathrm{V})$ is also a $\mathrm{d}^{0} \mathrm{~d}$-block cation, only ethylene $\rightarrow \mathrm{V}(\mathrm{V}) \sigma$ donation $\mathrm{DMF} \rightarrow \mathrm{V}(\mathrm{V}) \pi$-donation are possible. As a small and pentavalent $\mathrm{d}$-block cation, polarization of the reactants is significant and results in strong interactions. The normal and inverse demand energy gap have become 1.15 and $3.55 \mathrm{eV}$ for the ethylene-based reaction, respectively (Figure 3 ). Those of the DMF-based reaction are 6.64 and $0.11 \mathrm{eV}$, respectively.

Both for the ethylene- and the DMF-based reaction, the initial state is very stable, being $-253\left(\mathbf{1}_{\mathrm{C} 2}\right)$ and $-293\left(\mathbf{1}_{\mathrm{DMF}}\right)$ $\mathrm{kJ} / \mathrm{mol}$, respectively. Formation of the first $\mathrm{C}-\mathrm{C}$ bond results in a dormant state $\mathbf{2}_{\mathrm{C} 2}$ or $\mathbf{2}_{\mathrm{DMF}}$, with energies of -378 and $-394 \mathrm{~kJ} / \mathrm{mol}$, respectively. As a lot of energy has to be invested (188 and $155 \mathrm{~kJ} / \mathrm{mol}$ for the $\mathrm{C}_{2^{-}}$and DMF-based reactions, respectively) in releasing the strongly bound reactive complex from the $\mathrm{V}(\mathrm{V})$ cation, no activation energy could be determined. Note that $\mathbf{I}_{\mathrm{DMF}}$ is characterized by an intermediate resembling 2-oxabicyclo[2.2.1] hepta-1(7),3-diene coordinated via $\mathrm{C} 2$ to the $\mathrm{V}(\mathrm{V})$ active site. This illustrates the significant activation of the $\mathrm{C} 1-\mathrm{C} 2$ and $\mathrm{C} 2-\mathrm{C} 3$ conjugated bonds making both $\mathrm{C} 1$ and $\mathrm{C} 3$ very reactive.

Bond orders in $\mathbf{1}_{\mathrm{C} 2}$ for $\mathrm{V}(\mathrm{V})-\mathrm{C} 5 / \mathrm{V}(\mathrm{V})-\mathrm{C} 6$ are $0.17 / 0.16$, Figure 7. A strong vanadium-carbon interaction is formed, evidenced by $\mathrm{V}(\mathrm{V})-\mathrm{C} 5 / \mathrm{V}(\mathrm{V})-\mathrm{C} 6 \mathrm{BOs}$ or $0.47 / 0.01$ in $\mathrm{I}_{\mathrm{C} 2}$. Formation of the DAC adduct reduces these values to 0.12 / 0.11. Meanwhile, $\mathrm{C} 1-\mathrm{C} 6 / \mathrm{C} 4-\mathrm{C} 5$ bond orders are 0.9/0.02 in $\mathrm{I}_{\mathrm{C} 2}$ and change to $0.46 / 0.52$ in $\mathbf{2}_{\mathrm{C} 2}$. For the DMF-based reaction, $\mathrm{V}(\mathrm{V})-\mathrm{C} 2 / \mathrm{V}(\mathrm{V})-\mathrm{C} 3 \mathrm{BOs}$ are $0.22 / 0.18$, reach a significant $1.01 / 0.43$ in $\mathrm{I}_{\mathrm{DMF}}$ and reduce to $0.09 / 0.15$ in $2_{\mathrm{DMF}}$. The bond orders for $\mathrm{C} 1-\mathrm{C} 6 / \mathrm{C} 4-\mathrm{C} 5$ are $0.06 / 0.93$ in $\mathbf{I}_{\mathrm{DMF}}$ and $0.83 / 0.85$ in $\mathbf{2}_{\mathrm{DMF}}$.

\section{SUMMARY AND DISCUSSION}

The DAC reaction can proceed via the one- or two-step pathway in first row d-block exchanged faujasites. The TM cation d-shell filling and the steric constraints imposed by the zeolite framework directly influence the reaction mechanism. The DAC reaction is preceded by $\eta^{2}$-coordination of the primary reactant to the active site. The $\eta^{1}$-coordination and consequently the activation of the primary adsorbent initiates the two-step pathway.

Among the evaluated models, only in $\mathrm{Cu}(\mathrm{I}) \mathrm{FAU}$ is the synchronous concerted one-step pathway found involving $\mathbf{1}$, TS and 2 for both the ethylene- and DMF-based reaction.

Additionally, only in $\mathrm{Cu}(\mathrm{II})$ - and $\mathrm{Zn}$ (II)FAU does the ethylene-based reaction proceed via the two-step pathway involving 1, TS1, I, TS2, and 2. The DMF-based reaction in $\mathrm{Cu}$ (II)FAU follows a two-step pathway too. When using $\mathrm{Zn}$ (II)FAU, formation of a $\eta^{1}$-coordinated reactive complex is not possible in the DMF-based reaction due to steric hindrance created by the framework. This induces an asynchronous one-step pathway for the DMF-based reaction.

The effects of TM cation...substrate interactions and steric factors due to the interactions between substrates and the framework are well illustrated by the different behavior of $\mathrm{Cu}(\mathrm{I})-, \mathrm{Cu}(\mathrm{II})-$, and $\mathrm{Zn}(\mathrm{II}) \mathrm{FAU}$ systems in the DAC reaction. Geometries of the selected transition state and intermediate structures in $\mathrm{Cu}(\mathrm{I})-, \mathrm{Cu}(\mathrm{II})-$, and $\mathrm{Zn}(\mathrm{II}) \mathrm{FAU}$ are shown in Figure 8. Cation dislocations in the $z$-direction with respect to the plane parallel to the atoms making up the FAU 6MR are shown in addition to cation $\cdots$ reactive complex interaction 


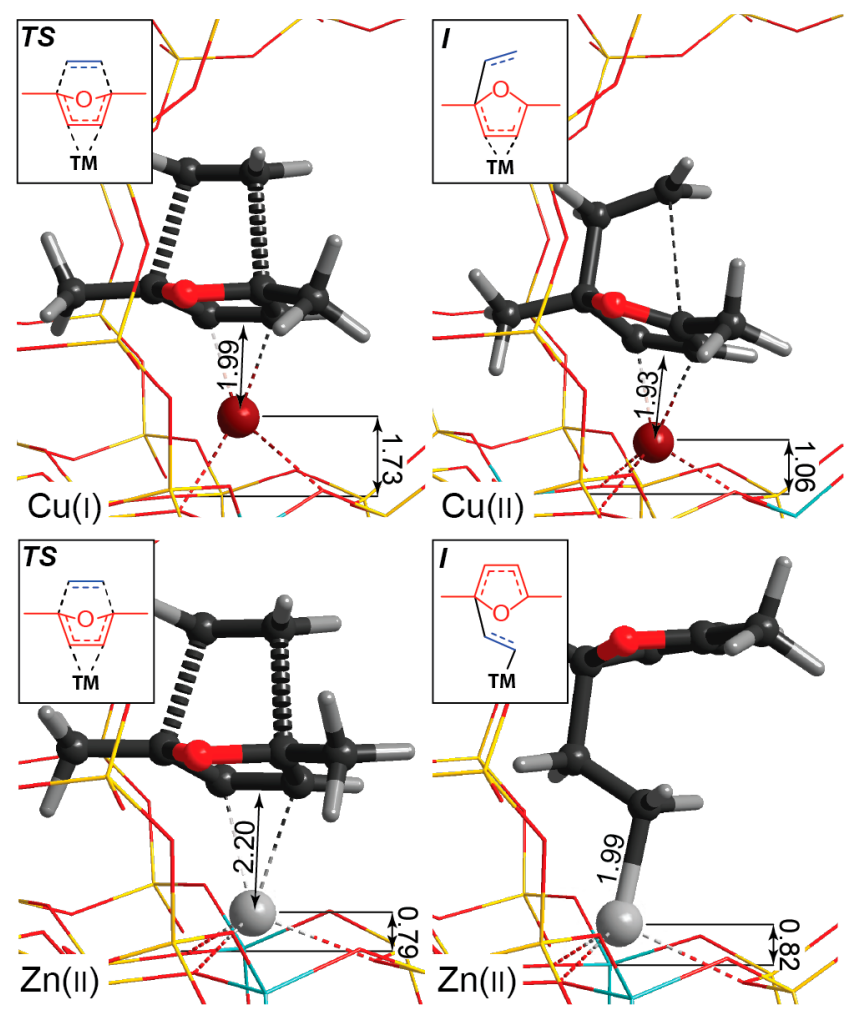

Figure 8. Structures of $\mathrm{TS}_{\mathrm{DMF}} / \mathrm{Cu}(\mathrm{I}) \mathrm{FAU}, \mathrm{I}_{\mathrm{DMF}} / \mathrm{Cu}(\mathrm{II}) \mathrm{FAU}, \mathrm{TS}_{\mathrm{DMF}} /$ $\mathrm{Zn}(\mathrm{II}) \mathrm{FAU}$ and $\mathbf{I}_{\mathrm{C} 2} / \mathrm{Zn}$ (II)FAU. All distances are in A. Cation $\cdots 6 \mathrm{MR}$ distances defined as the absolute change in z-position with respect to

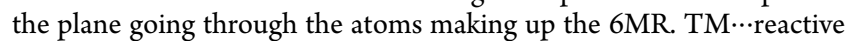
complex interaction distances are also shown.

distances. The three cations adopt substantially different configurations within the zeolite $6 \mathrm{MR}$ sites resulting in a different shielding by lattice oxygen atoms and, accordingly, different effective accessibility of the exchangeable cation. The data in Figure 8 show that $\mathrm{Zn}$ (II) occupies a highly shielded central position within the $6 \mathrm{MR}$ site of FAU, while $\mathrm{Cu}(\mathrm{I})$ effectively sits above the zeolite ring and $\mathrm{Cu}(\mathrm{II})$ adopts a position intermediate to the two other extreme cases.

The $\eta^{2}$-coordination of ethylene to the exposed $\mathrm{Cu}(\mathrm{I})$ cation can be described in the framework of the classical DewarChatt-Duncanson model, according to which the bonding within the adsorption complex stems from the $\mathrm{Cu}(\mathrm{I}) \leftarrow$ ethylene $\sigma$-donor and $\mathrm{Cu}(\mathrm{I}) \rightarrow$ ethylene $\pi$-acceptor interactions. The latter orbital interaction is established between the $d_{x z} / d_{y z}$ orbitals of $\mathrm{Cu}(\mathrm{I})$ and the ethylene LUMO. For the DMF-based reaction, the binding in the adsorption complexes is aided through the $\mathrm{Cu}(\mathrm{I}) \rightarrow \mathrm{DMF} \sigma$ acceptor-type interactions. These are provided through the overlap between the $\mathrm{Cu}(\mathrm{I}) 3 \mathrm{~d}_{\mathrm{z}}^{2}$ orbital and the DMF LUMO. The symmetry of the $3 \mathrm{~d}_{\mathrm{z}}{ }^{2}$ orbital allows for both $\eta^{1}$ - or $\eta^{2}$-type coordination. The cylcoadduct in $\mathbf{T S}_{\mathrm{DMF}}$ qualitatively exhibits orbital symmetry similar to that of ethylene in $\mathbf{1}_{\mathrm{C} 2}$, Figure S1. Thus, we hypothesize that the $\eta^{2}$-coordination of the reactive complex in $\mathrm{TS}_{\mathrm{DMF}}$ to the accessible $\mathrm{Cu}(\mathrm{I})$ cation enables a one-step mechanism. Additionally, the kinetic preference for either the ethylene- or DMF-based pathway is governed by the stability of the respective $\mathbf{T S}$ structures. In $\mathbf{T S}_{\mathrm{C} 2}$, the orbital symmetry of the reactive complex is inappropriate for suitable orbital interactions and is consequently higher in energy than $\mathrm{TS}_{\mathrm{DMF}}$.
The reactive site in $\mathrm{Cu}(\mathrm{II}) \mathrm{FAU}$ is in the $\mathrm{d}^{9}$ electron configuration. The analysis of the spin density in the intermediates along the DAC path (Figure $5 \mathrm{~h}$ ) suggests a partial reduction of $\mathrm{Cu}(\mathrm{II})$ upon the formation of a $\mathrm{Cu}-\mathrm{C}$ bond to produce a $\mathrm{C}$-centered radical intermediate. Because the cation is sufficiently accessible to both the relatively large DMF and small $\mathrm{C}_{2} \mathrm{H}_{4}$ moieties, the reaction can proceed via a two-step pathway involving 1, TS1, I, TS2, and 2. Orbital symmetry considerations in line with those for the $\mathbf{T S}_{\mathrm{c} 2} / \mathbf{T S}_{\mathrm{DMF}}$ in $\mathrm{Cu}(\mathrm{I}) \mathrm{FAU}$ dictate the kinetic preference for the DMF-based pathway in $\mathrm{Cu}(\mathrm{II}) \mathrm{FAU}$.

For the DAC reaction in $\mathrm{Zn}$ (II)FAU, the $\mathrm{Zn}(\mathrm{II}) \cdots$ substrate interactions are exclusively governed by the overlap between $\mathrm{Zn}$ (II) $4 \mathrm{~s}$ orbital and the substrate FMOs. The 3d-orbitals lie too deep in energy to play any significant role in bonding (Figure 3 and Figure 4). Because $\mathrm{Zn}$ (II) is effectively embedded into the $6 \mathrm{MR}$, only ethylene can coordinate to it and form relatively strong $\mathrm{Zn}-\mathrm{C}$ contacts. In the case of the DMF-based pathway over $\mathrm{Zn}$ (II)FAU, the formation of a tightly bound $\eta^{1}$-coordination complex is sterically hindered. This results in a higher $\mathbf{T S}_{\mathrm{DMF}}$ energy compared to $\mathbf{T S}_{\mathrm{C} 2}$ and the DMF-based DAC reaction proceeds via an asynchronous concerted one-step mechanism.

Similar reasoning allows for rationalization of the differences in the preferred mechanistic paths for other cations considered in this study. However, the substantial cationic charge along with the partially filled $3 \mathrm{~d}$-shells allow for a stronger substrate coordination compared to that established with the late dblock metal cations. As a result, for $\mathrm{Ni}(\mathrm{II})-, \mathrm{Cr}(\mathrm{III})-, \mathrm{Sc}(\mathrm{III})-$, and $\mathrm{V}(\mathrm{V}) \mathrm{FAU}$ the ethylene-based reaction follows a two-step pathway lacking TS1, I, TS2, or a combination thereof.

For instance, in $\mathrm{Cr}$ (III)FAU, no TS1 is found. The lack of TS1 is attributed to the significant activation of the reactant upon adsorption as indicated by the small energy gaps in $\mathbf{1}$ resulting from the efficient orbital overlap interactions. The computed bond orders indicate that the identified pathways belong to a two-step mechanism. For example, the C2-based reaction in $\mathrm{Cu}(\mathrm{I}) \mathrm{FAU}$ follows a one-step mechanism with $\mathrm{C1}-$ C6/C4-C5 BOs 0.36/0.32. In contrast, the C4-C5 BOs in $\mathbf{I}_{\mathrm{C} 2}$ in $\mathrm{Cr}(\mathrm{III})_{-}, \mathrm{Sc}(\mathrm{III})$-, and $\mathrm{V}(\mathrm{V}) \mathrm{FAU}$ are close to zero. Another example is $\mathbf{T S} \mathbf{2}_{\mathrm{C} 2}$ in $\mathrm{Ni}(\mathrm{II}) \mathrm{FAU}$ and $\mathrm{Sc}(\mathrm{III}) \mathrm{FAU}$, for which we find $\mathrm{BOs}$ of $0.29 / 0.83$ and $0.71 / 0.23$ for $\mathrm{C} 1-\mathrm{C} 6 /$ C4-C5, respectively. The high BOs of ca. $0.7-0.8$ for one of the $\mathrm{C}-\mathrm{C}$ bonds in $\mathrm{TS}_{\mathrm{C} 2}$ is the main motivation for disregarding this state as corresponding to an asynchronous concerted one-step mechanism. Such a high bond order suggests that one of the bonds is much more evolved in the transition state than found for the synchronous concerted onestep reaction in this work (e.g., the DAC reaction over $\mathrm{Cu}(\mathrm{I}) \mathrm{FAU})$.

The DMF-based reaction over $\mathrm{Sc}$ (III)FAU is mechanistically similar to that established for $\mathrm{Zn}$ (II)FAU. The steric hindrance between the reactive complex and the framework in this case also enforces an asynchronous one-step mechanism. When the strongly electrophilic $\mathrm{V}(\mathrm{V})$-cation is the active site, intermediate I becomes a dormant state for both the ethyleneand DMF-based reactions.

To put these results in perspective, the framework $\cdots$ substrate interactions are very similar to the steric interactions that substrates experience in enzymes and supramolecular complexes. ${ }^{60-66}$ For the studied DAC reaction in this work, such interactions have no effect on regio- and stereoselectivity. It is hypothesized, though, that DAC reactions between substituted 
dienes and/or dienophiles may experience a change in regioand stereoselectivity. For instance, we expect that the formation of the anti-intermediate as reported for the twostep diradical DAC reaction between 1,3-butadiene and ethylene in the gas phase ${ }^{100}$ does not take place in the current systems due to the stabilizing dispersion ethylene...zeolite framework interactions and pronounced steric hindrance due to the DMF methyl groups. Furthermore, the equatorial coordination sites of the TM cations are occupied by the framework oxygen atoms in all models. Thus, in contrast to homogeneous TM-based catalysts, ${ }^{48,56,58,59}$ neither metallacycles can be formed nor can the second reactant be coordinated prior to the DAC reaction.

The increasing activation of reactants upon a decreasing $d$ shell electron occupation is illustrated by the energy gaps. Energy gaps in the $3 \mathrm{~d}^{10}-\mathrm{TM}$ cations $\mathrm{Cu}(\mathrm{I})$ - and $\mathrm{Zn}(\mathrm{II}) \mathrm{FAU}$ range from 2.59 to $5.57 \mathrm{eV}$. For $\mathrm{Cu}(\mathrm{II}) \mathrm{FAU}, e_{\mathrm{inv}, \mathrm{C}_{2}}\left(e_{\text {norm, DMF }}\right)$ is $0.64 \mathrm{eV}(1.06 \mathrm{eV})$ with the other energy gaps higher than 4 eV. For Ni(II)-, Cr(III)-, Sc(III)-, and V(V)FAU, at least one energy gap is below $1.16 \mathrm{eV}$ in both the ethylene- and DMFbased reactions. This significant activation is the reason that TS1 in the two-step pathway is generally absent in these systems. To put this in context, the reported TMFAU energy gaps are significantly lower than those in alkali-exchanged faujasites $(>5 \mathrm{eV}) .^{45}$

The DAC activation energies in the evaluated TMFAU catalysts for the majority of the two-step pathways are in the order of $10-50 \mathrm{~kJ} / \mathrm{mol}$. For I $\rightarrow$ TS2 and I $\rightarrow$ II in the ethylene-based reaction over $\mathrm{Cu}$ (II)FAU and $\mathrm{Cr}$ (III)FAU, we found barriers of 92 and $108 \mathrm{~kJ} / \mathrm{mol}$, respectively. Activation barriers associated with the one-step pathway range between 54 to $144 \mathrm{~kJ} / \mathrm{mol}$. For instance, the DMF-based one-step reaction in $\mathrm{Cu}(\mathrm{I}) \mathrm{FAU}, \mathrm{Zn}$ (II)FAU, and $\mathrm{Sc}(\mathrm{III}) \mathrm{FAU}$ exhibits barriers of 54, 65, and $82 \mathrm{~kJ} / \mathrm{mol}$. Thus, most of the two-step pathways over TMFAU proceed with activation barriers lower than those previously reported for high- and low-silica alkaliexchanged faujasites $(70-110 \mathrm{~kJ} / \mathrm{mol}) .^{25-27,45}$ In general, the activation barriers along the one-step paths are reminiscent to those found for alkali-exchanged faujasites.

The observed activation of double bonds in this work is in accordance with the existing DAC-theory on diene/dienophile activation by electron-withdrawing and -donating groups. ${ }^{101}$ Upon $\eta^{1}$-coordination of ethylene in TS1, the terminal carbon atom is activated and participates in the formation of the first $\mathrm{C}-\mathrm{C}$ bond. Similarly, the carbon atoms next to $\mathrm{C}_{\mathrm{TM}}$ are activated when DMF is $\eta^{1}$-coordinated. For instance, when C2 is $\mathrm{C}_{\mathrm{TM}}$, the $\mathrm{C} 1-\mathrm{C} 5$ bond is the first bond to form. Additionally, in V(V)FAU, 2-oxabicyclo[2.2.1] hepta-1(7),3diene is formed rather than 1,4-dimethyl-7-oxabicyclo[2.2.1]hept-2-ene as a consequence of significant activation of $\mathrm{C} 3$.

The computed bond orders indicate strong TM-C5/ TM-C6 and TM-C2/TM-C3 interactions in $\mathbf{1}_{\mathrm{DMF}}$ and $\mathbf{1}_{\mathrm{C} 2}$, respectively. Typically, $\mathrm{BOs}$ in $\mathbf{1}_{\mathrm{C} 2}$ and $\mathbf{1}_{\mathrm{DMF}}$ are similar and range between 0.1 and 0.5 . However, $2_{\mathrm{DMF}}$ is usually more stable than $\mathbf{2}_{\mathrm{C} 2}$. This is attributed to the fact that during the reaction the $\mathrm{C} 2 / \mathrm{C} 3$ carbon atoms remain $\mathrm{sp}^{2}$-hybridized, whereas the hybridization of $\mathrm{C} 5 / \mathrm{C} 6$ changes to $\mathrm{sp}^{3}$ resulting in an orbital mismatch with the d-orbitals of the TM cation. Consequently, BOs in $2_{\mathrm{DMF}}$ are more than 1.5 times larger than those in $2_{\mathrm{C} 2}$. The loss of $\mathrm{C} 5 / \mathrm{C} 6 \mathrm{sp}^{2}$-hybridization and consequently the loss of appropriate orbital symmetry for interaction with the cation d-orbitals explains the relatively high $E_{\text {act,TS2 } \rightarrow 2}$ and $E_{\text {act, I } \rightarrow \text { II }}$ for the ethylene-based reaction and very similar energies for $\mathbf{T S} \mathbf{2}_{\mathrm{C} 2} / \mathbf{2}_{\mathrm{C} 2}$ and $\mathbf{I I} / \mathbf{2}_{\mathrm{C} 2}$ pairs in $\mathrm{Ni}(\mathrm{II})$ and $\mathrm{Cr}(\mathrm{III}) \mathrm{FAU}$, respectively.

Considering the discussion above, we propose that the DAC reactivity of the TMFAU model catalysts can be rationalized by the d-block donor-acceptor properties and orbital symmetry considerations. The metal cations with less filled d-shells bind the unsaturated substrates stronger due to both the increased ability to accept electrons from the adsorbed species and the increase in net cationic charge. Both these effects contribute to the enhanced substrate activation.

Carbon rehybridization in the course of the DAC reaction dictates to which extend the favorable TM $\rightarrow$ substate donoracceptor interactions can be maintained. For the ethylenebased reactions, carbon rehybridization reduces the effective orbital overlap, while it is maintained in the DMF-based paths resulting in a reduced stability of the species formed along the ethylene-based path. The DMF-based reaction channel in the case of small d-metal cations suffers from pronounced steric hindrance excreted by the zeolite framework, which effectively counteracts the favorable orbital symmetries.

\section{CONCLUSIONS}

Herein, we reported on a periodic DFT study focused on a mechanistic understanding of the DAC reaction between DMF and ethylene using first row d-block metal cation $(\mathrm{TM}=$ $\mathrm{Cu}(\mathrm{I}), \mathrm{Cu}(\mathrm{II}), \mathrm{Zn}(\mathrm{II}), \mathrm{Ni}(\mathrm{II}), \mathrm{Cr}(\mathrm{III}), \mathrm{Sc}(\mathrm{III}), \mathrm{V}(\mathrm{V}))$ exchanged high-silica faujasite catalysts. Changes to the DAC reaction mechanism as a function of the d-shell occupation were discussed. The TM $\cdots$ reactant interactions were quantified using the COHP- and COOP-functions and the DDEC6-based bond order analysis.

Due to the symmetry of the TM cation d-orbitals, $\sigma$-donor/ acceptor and $\pi$-donor/acceptor interactions can be established with both the DMF and ethylene FMOs. An increase in reactant activation is found upon a decrease in d-shell filling. This is evidenced by the resulting small energy gaps and low activation energies.

$\mathrm{Cu}$ (II)FAU, Ni(II)FAU, and Cr(III)FAU catalyzed both the ethylene- and DMF-based DAC reactions via a two-step pathway. In $\mathrm{Zn}$ (II)FAU and $\mathrm{Sc}$ (III)FAU, a two-step pathway was observed for the $\mathrm{C} 2$-based reaction while an asynchronous one-step pathway for the DMF-based reaction was found. This change in mechanism is attributed to the small radii of the cations which are less accessible for the DMF-based reactive complex due to steric hindrance with the framework. Both the ethylene- and DMF-based DAC reaction in $\mathrm{Cu}(\mathrm{I}) \mathrm{FAU}$ exhibited a one-step DAC-reaction mechanism. The $\mathrm{Cu}(\mathrm{I})$ cation shows an enhanced accessibility to both primary adsorbents. The orbital symmetries in $\mathbf{1}_{\mathrm{C} 2}$ and $\mathbf{T S} \mathbf{S}_{\mathrm{DMF}}$ enable the DAC reaction to proceed via a one-step mechanism. The highly electrophilic $\mathrm{V}(\mathrm{V})$ cation causes the formation of a dormant intermediate state.

This work is an example of how reactivity and reaction mechanisms are influenced by the properties of the active site and the direct chemical environment exerting steric constraints on the reactive complex.

\section{ASSOCIATED CONTENT}

\section{S Supporting Information}

The Supporting Information is available free of charge on the ACS Publications website at DOI: 10.1021/acscatal.8b03482. 
Representation of DFT-computed ethylene, DMF, and DAC cycloadduct HOMOs and LUMOs; ethylenebased two-step pathway; atomic spin densities in $\mathrm{Cu}(\mathrm{II}) \mathrm{FAU}, \mathrm{Cr}(\mathrm{III}) \mathrm{FAU}$, and $\mathrm{Ni}(\mathrm{II}) \mathrm{FAU}$; selected $\mathrm{TM}-\mathrm{C}$ and $\mathrm{C}-\mathrm{C}$ bond orders; visualization of charge density difference in $\mathrm{V}(\mathrm{V}) \mathrm{FAU}$; and all optimized geometries in all evaluated TMFAU catalysts (PDF)

\section{AUTHOR INFORMATION}

\section{Corresponding Authors}

*E-mail: e.j.m.hensen@tue.nl (E.J.M.H.).

*E-mail: e.a.pidko@tudelft.nl (E.A.P.).

\section{ORCID}

Emiel J. M. Hensen: 0000-0002-9754-2417

Evgeny A. Pidko: 0000-0001-9242-9901

\section{Present Address}

"E.A.P.: Inorganic Systems Engineering group, Department of Chemical Engineering, Faculty of Applied Sciences, Delft University of Technology, Van der Maasweg 9, 2629 HZ Delft, The Netherlands

\section{Notes}

The authors declare no competing financial interest.

\section{ACKNOWLEDGMENTS}

This work was supported by The Netherlands Center for Multiscale Catalytic Energy Conversion (MCEC), an NWO Gravitation programme funded by the Ministry of Education, Culture and Science of the government of The Netherlands. The authors also thank The Netherlands Organization for Scientific Research (NWO) for access to the national highperformance computing facilities.

\section{REFERENCES}

(1) Diels, O.; Alder, K. Synthesen in Der Hydroaromatischen Reihe. Leibigs Ann. Chem. 1928, 460, 98-122.

(2) Tasdelen, M. A. Diels-Alder "click" Reactions: Recent Applications in Polymer and Material Science. Polym. Chem. 2011, 2, 2133-2145.

(3) Heravi, M. M.; Ahmadi, T.; Ghavidel, M.; Heidari, B.; Hamidi, $\mathrm{H}$. Recent Applications of the Hetero Diels-Alder Reaction in the Total Synthesis of Natural Products. RSC Adv. 2015, 5, 101999102075.

(4) Nicolaou, K. C.; Snyder, S. A.; Montagnon, T.; Vassilikogiannakis, G. The Diels - Alder Reaction in Total Synthesis. Angew. Chem., Int. Ed. 2002, 41, 1668.

(5) Kappe, C. O.; Murphree, S. S.; Padwa, A. Synthetic Applications of Furan Diels-Alder Chemistry. Tetrahedron 1997, 53, 14179-14233.

(6) Funel, J.-A.; Abele, S. Industrial Applications of the Diels-Alder Reaction. Angew. Chem., Int. Ed. 2013, 52, 3822-3863.

(7) Peterson, A. M.; Jensen, R. E.; Palmese, G. R. RoomTemperature Healing of a Thermosetting Polymer Using the DielsAlder Reaction. ACS Appl. Mater. Interfaces 2010, 2, 1141-1149.

(8) Zeng, C.; Seino, H.; Ren, J.; Hatanaka, K.; Yoshie, N. Bio-Based Furan Polymers with Self-Healing Ability. Macromolecules 2013, 46, 1794-1802.

(9) Houk, K. N.; Gonzalez, J.; Li, Y. Pericyclic Reaction Transition States: Passions and Punctilios, 1935-1995. Acc. Chem. Res. 1995, 28 , 81-90.

(10) Houk, K. N.; Li, Y.; Evanseck, J. D. Transition Structures of Hydrocarbon Pericyclic Reactions. Angew. Chem., Int. Ed. Engl. 1992, $31,682-708$.

(11) Domingo, L. R.; José Aurell, M.; Pérez, P.; Contreras, R. Origin of the Synchronicity on the Transition Structures of Polar Diels-Alder
Reactions. Are These Reactions $[4+2]$ Processes? J. Org. Chem. 2003, 68, 3884-3890.

(12) Houk, K. N. The Frontier Molecular Orbital Theory of Cycloaddition Reactions. Acc. Chem. Res. 1975, 8, 361-369.

(13) Hoffmann, R.; Woodward, R. B. Selection Rules for Concerted Cycloaddition Reactions. J. Am. Chem. Soc. 1965, 87, 2046-2048.

(14) Hoffmann, R.; Woodward, R. B. The Conservation of Orbital Symmetry. Acc. Chem. Res. 1968, 1, 17-22.

(15) Mccarrick, M. A.; Wu, Y. D.; Houk, K. N. Hetero-Diels-Alder Reaction Transition Structures - Reactivity, Stereoselectivity, Catalysis, Solvent Effects, and the Exo-Lone-Pair Effect. J. Org. Chem. 1993, 58, 3330-3343.

(16) Houk, K. N.; Strozier, R. W. Lewis Acid Catalysis of Diels-Alder Reactions. J. Am. Chem. Soc. 1973, 95, 4094-4096.

(17) Brion, F. On the Lewis Acid Catalyzed Diels-Alder Reaction of Furan. Regio- and Stereospecific Synthesis of Substituted Cyclohexenols and Cyclohexadienols. Tetrahedron Lett. 1982, 23, 52995302.

(18) Cook, M. J.; Cracknell, S. J. The Diels-Alder Reaction of 2,5Dialkylfurans and Fumaronitrile Revisited. Tetrahedron 1994, 50, 12125-12132.

(19) Vogel, P.; Cossy, J.; Plumet, J.; Arjona, O. Derivatives of 7oxabicyclo[2.2.1]heptane in Nature and as Useful Synthetic Intermediates. Tetrahedron 1999, 55, 13521-13642.

(20) Besson, M.; Gallezot, P.; Pinel, C. Conversion of Biomass into Chemicals over Metal Catalysts. Chem. Rev. 2014, 114, 1827-1870.

(21) van Putten, R.-J.; van der Waal, J. C.; de Jong, E.; Rasrendra, C. B.; Heeres, H. J.; de Vries, J. G. Hydroxymethylfurfural, A Versatile Platform Chemical Made from Renewable Resources. Chem. Rev. 2013, 113, 1499-1597.

(22) Settle, A. E.; Berstis, L.; Rorrer, N. A.; Roman-Leshkóv, Y.; Beckham, G. T.; Richards, R. M.; Vardon, D. R. Heterogeneous Diels-Alder Catalysis for Biomass-Derived Aromatic Compounds. Green Chem. 2017, 19, 3468-3492.

(23) Fabri, J.; Graeser, U.; Simo, T. A. Xylenes. In Ullmann's Encyclopedia of Industrial Chemistry; Bailey, J. E. et al., Eds.; WileyVCH Verlag GmbH \& Co. KGaA: Weinheim, Germany, 2000; pp 643-664.

(24) Folkins, H. O. Benzene. In Ullmann's Encyclopedia of Industrial Chemistry; Bailey, J. E. et al., Eds.; Wiley-VCH Verlag GmbH \& Co. KGaA: Weinheim, Germany, 2000; Vol. 100C, pp 41-93.

(25) Rohling, R. Y.; Uslamin, E.; Zijlstra, B.; Tranca, I. C.; Filot, I. A. W.; Hensen, E. J. M.; Pidko, E. A. An Active Alkali-Exchanged Faujasite Catalyst for P -Xylene Production via the One-Pot DielsAlder Cycloaddition/Dehydration Reaction of 2,5-Dimethylfuran with Ethylene. ACS Catal. 2018, 8, 760-769.

(26) Rohling, R. Y.; Hensen, E. J. M.; Pidko, E. A. Multi-Site Cooperativity in Alkali-Metal-Exchanged Faujasites for the Production of Biomass-Derived Aromatics. ChemPhysChem 2018, 19, 446458.

(27) Nikbin, N.; Feng, S.; Caratzoulas, S.; Vlachos, D. G. P- Xylene Formation by Dehydrative Aromatization of a Diels-Alder Product in Lewis and Brønsted Acidic Zeolites. J. Phys. Chem. C 2014, 118, 24415-24424.

(28) Nikbin, N.; Do, P. T.; Caratzoulas, S.; Lobo, R. F.; Dauenhauer, P. J.; Vlachos, D. G. A DFT Study of the Acid-Catalyzed Conversion of 2,5-Dimethylfuran and Ethylene to P-Xylene. J. Catal. 2013, 297, $35-43$.

(29) Wijaya, Y. P.; Kristianto, I.; Lee, H.; Jae, J. Production of Renewable Toluene from Biomass-Derived Furans via Diels-Alder and Dehydration Reactions: A Comparative Study of Lewis Acid Catalysts. Fuel 2016, 182, 588-596.

(30) Mahmoud, E. Synergistic Effect of Acidity and Extraframework Position in Faujasite on Renewable P -Xylene Production. R. Soc. Open Sci. 2018, 5, 172471.

(31) Patet, R. E.; Fan, W.; Vlachos, D. G.; Caratzoulas, S. Tandem Diels-Alder Reaction of Dimethylfuran and Ethylene and Dehydration to Para-Xylene Catalyzed by Zeotypic Lewis Acids. ChemCatChem 2017, 9, 2523-2535. 
(32) Patet, R. E.; Caratzoulas, S.; Vlachos, D. G. Tandem Aromatization of Oxygenated Furans by Framework Zinc in Zeolites. A Computational Study. J. Phys. Chem. C 2017, 121, 22178-22186.

(33) Salavati-Fard, T.; Caratzoulas, S.; Lobo, R. F.; Doren, D. J. Catalysis of the Diels-Alder Reaction of Furan and Methyl Acrylate in Lewis Acidic Zeolites. ACS Catal. 2017, 7, 2240-2246.

(34) Li, Y.-P.; Head-Gordon, M.; Bell, A. T. Theoretical Study of 4(Hydroxymethyl)benzoic Acid Synthesis from Ethylene and 5(Hydroxymethyl)furoic Acid Catalyzed by Sn-BEA. ACS Catal. 2016, 6, 5052-5061.

(35) Byrne, M. J.; Lees, N. R.; Han, L. C.; Van Der Kamp, M. W.; Mulholland, A. J.; Stach, J. E. M.; Willis, C. L.; Race, P. R. The Catalytic Mechanism of a Natural Diels-Alderase Revealed in Molecular Detail. J. Am. Chem. Soc. 2016, 138, 6095-6098.

(36) Pacheco, J. J.; Labinger, J. A.; Sessions, A. L.; Davis, M. E. Route to Renewable PET: Reaction Pathways and Energetics of Diels-Alder and Dehydrative Aromatization Reactions Between Ethylene and Biomass-Derived Furans Catalyzed by Lewis Acid Molecular Sieves. ACS Catal. 2015, 5, 5904-5913.

(37) Cheng, Y.-T.; Huber, G. W. Production of Targeted Aromatics by Using Diels-Alder Classes of Reactions with Furans and Olefins over ZSM-5. Green Chem. 2012, 14, 3114-3125.

(38) Do, P. T. M.; McAtee, J. R.; Watson, D. A.; Lobo, R. F. Elucidation of Diels-Alder Reaction Network of 2,5-Dimethylfuran and Ethylene on HY Zeolite Catalyst. ACS Catal. 2013, 3, 41-46.

(39) Chang, C.; Green, S. K.; Williams, C. L.; Dauenhauer, P. J.; Fan, W. Ultra-Selective Cycloaddition of Dimethylfuran for Renewable P-Xylene with H-BEA. Green Chem. 2014, 16, 585-588.

(40) Ni, L.; Xin, J.; Jiang, K.; Chen, L.; Yan, D.; Lu, X.; Zhang, S. One-Step Conversion of Biomass-Derived Furanics into Aromatics by Brønsted Acid Ionic Liquids at Room Temperature. ACS Sustainable Chem. Eng. 2018, 6, 2541-2551.

(41) Genuino, H. C.; Thiyagarajan, S.; van der Waal, J. C.; de Jong, E.; van Haveren, J.; van Es, D. S.; Weckhuysen, B. M.; Bruijnincx, P. C. A. Selectivity Control in the Tandem Aromatization of Bio-Based Furanics Catalyzed by Solid Acids and Palladium. ChemSusChem 2017, 10, 277-286.

(42) Green, S. K.; Patet, R. E.; Nikbin, N.; Williams, C. L.; Chang, C. C.; Yu, J.; Gorte, R. J.; Caratzoulas, S.; Fan, W.; Vlachos, D. G.; et al. Diels-Alder Cycloaddition of 2-Methylfuran and Ethylene for Renewable Toluene. Appl. Catal., B 2016, 180, 487-496.

(43) Pacheco, J. J.; Davis, M. E. Synthesis of Terephthalic Acid via Diels-Alder Reactions with Ethylene and Oxidized Variants of 5Hydroxymethylfurfural. Proc. Natl. Acad. Sci. U. S. A. 2014, 111, $8363-8367$.

(44) Orazov, M.; Davis, M. E. Catalysis by Framework Zinc in SilicaBased Molecular Sieves. Chem. Sci. 2016, 7, 2264-2274.

(45) Rohling, R. Y.; Tranca, I. C.; Hensen, E. J. M.; Pidko, E. A. Electronic Structure Analysis of the Diels-Alder Cycloaddition Catalyzed by Alkali-Exchanged Faujasites. J. Phys. Chem. C 2018, 122, 14733-14743.

(46) Chang, C.-C.; Je Cho, H.; Yu, J.; Gorte, R. J.; Gulbinski, J.; Dauenhauer, P.; Fan, W. Lewis Acid Zeolites for Tandem DielsAlder Cycloaddition and Dehydration of Biomass-Derived Dimethylfuran and Ethylene to Renewable P-Xylene. Green Chem. 2016, 18, $1368-1376$

(47) Fringuelli, F.; Piermatti, O.; Pizzo, F.; Vaccaro, L. Recent Advances in Lewis Acid Catalyzed Diels-Alder Reactions in Aqueous Media. Eur. J. Org. Chem. 2001, 2001, 439-455.

(48) Liao, W.; Yu, Z. X. DFT Study of the Mechanism and Stereochemistry of the $\mathrm{Rh}(\mathrm{I})$-Catalyzed Diels-Alder Reactions between Electronically Neutral Dienes and Dienophiles. J. Org. Chem. 2014, 79, 11949-11960.

(49) Murakami, M.; Itami, K.; Ito, Y. Directed Intermolecular [4 + 2] Cycloaddition of Unactivated 1,3-Diene Substrates with High Regio- and Stereoselectivities. J. Am. Chem. Soc. 1997, 119, 71637164.
(50) Hilt, G.; Janikowski, J.; Hess, W. Meta-Directing CobaltCatalyzed Diels-Alder Reactions. Angew. Chem., Int. Ed. 2006, 45, 5204-5206.

(51) Olmos, A.; Louis, B.; Pale, P. Scandium(III)-Zeolites as New Heterogeneous Catalysts for Imino-Diels-Alder Reactions. Chem. Eur. J. 2012, 18, 4894-4901.

(52) Adams, J. M.; Dyer, S.; Martin, K.; Matear, W. A.; McCabe, R. W. Diels-Alder Reactions Catalysed by Cation-Exchanged Clay Minerals. J. Chem. Soc., Perkin Trans. 1 1994, 761-765.

(53) Dossetter, A. G.; Jamison, T. F.; Jacobsen, E. N. Highly Enantio- and Diastereoselective Hetero-Diels-Alder Reactions Catalyzed by New Chiral Tridentate Chromium (III) Catalysts. Angew. Chem., Int. Ed. 1999, 38, 2398-2400.

(54) Fürstner, A.; Stimson, C. C. Two Manifolds for MetalCatalyzed Intramolecular Diels-Alder Reactions of Unactivated Alkynes. Angew. Chem., Int. Ed. 2007, 46, 8845-8849.

(55) Kobayashi, S. Scandium Triflate in Organic Synthesis. Eur. J. Org. Chem. 1999, 1999, 15-27.

(56) Lautens, M.; Klute, W.; Tam, W. Transition Metal-Mediated Cycloaddition Reactions. Chem. Rev. 1996, 96, 49-92.

(57) Jiang, B.; Liang, Q.-J.; Han, Y.; Zhao, M.; Xu, Y.-H.; Loh, T.-P. Copper-Catalyzed Dehydrogenative Diels-Alder Reaction. Org. Lett. 2018, 20, 3215-3219.

(58) Mörschel, P.; Janikowski, J.; Hilt, G.; Frenking, G. LigandTuned Regioselectivity of a Cobalt-Catalyzed Diels-Alder Reaction. A Theoretical Study. J. Am. Chem. Soc. 2008, 130, 8952-8966.

(59) Huang, G. Mechanism and Selectivity in Rhodium-Catalyzed [7 + 2] Cycloaddition and Cyclopropanation/Cyclization of Allenylcyclopentane-Alkynes: Metallacycle-Directed C(sp3)-C(sp3) vs C(sp3)-H Activation. J. Org. Chem. 2015, 80, 7564-7571.

(60) Oikawa, H.; Tokiwano, T. Enzymatic Catalysis of the DielsAlder Reaction in the Biosynthesis of Natural Products. Nat. Prod. Rep. 2004, 21, 321-352.

(61) Ose, T.; Watanabe, K.; Mie, T.; Honma, M.; Watanabe, H.; Yao, M.; Oikawa, H.; Tanaka, I. Insight into a Natural Diels-Alder Reaction from the Structure of Macrophomate Synthase. Nature 2003, 422, 185-189.

(62) Heine, A.; Stura, E. A.; Yli-Kauhaluoma, J. T.; Gao, C.; Deng, Q.; Beno, B. R.; Houk, K. N.; Janda, K. D.; Wilson, I. A. An Antibody Exo Diels-Alderase Inhibitor Complex at 1.95 Angstrom Resolution. Science 1998, 279, 1934-1940.

(63) Siegel, J. B.; Zanghellini, A.; Lovick, H. M.; Kiss, G.; Lambert, A. R.; St. Clair, J. L.; Gallaher, J. L.; Hilvert, D.; Gelb, M. H.; Stoddard, B. L.; et al. Computational Design of an Enzyme Catalyst for a Stereoselective Bimolecular Diels-Alder Reaction. Science 2010, $329,309-313$.

(64) Yoshizawa, M.; Tamura, M.; Fujita, M. Diels-Alder in Aqueous Molecular. Science 2006, 312, 251-254.

(65) Murase, T.; Horiuchi, S.; Fujita, M. Naphthalene Diels - Alder in a Self-Assembled Molecular Flask. J. Am. Chem. Soc. 2010, 132, $2866-2867$

(66) Hatano, M.; Ishihara, K. Conformationally Flexible Chiral Supramolecular Catalysts for Enantioselective Diels-Alder Reactions with Anomalous Endo/exo Selectivities. Chem. Commun. 2012, 48, $4273-4283$.

(67) Smit, B.; Maesen, T. L. M. Towards a Molecular Understanding of Shape Selectivity. Nature 2008, 451, 671-678.

(68) Rozanska, X.; Fortrie, R.; Sauer, J. Size-Dependent Catalytic Activity of Supported Vanadium Oxide Species: Oxidative Dehydrogenation of Propane. J. Am. Chem. Soc. 2014, 136, 7751-7761.

(69) Frising, T.; Leflaive, P. Extraframework Cation Distributions in X and Y Faujasite Zeolites: A Review. Microporous Mesoporous Mater. 2008, 114, 27-63.

(70) Kresse, G.; Hafner, J. Ab Initio Molecular-Dynamics Simulation of the Liquid-Metal-amorphous-Semiconductor Transition in Germanium. Phys. Rev. B: Condens. Matter Mater. Phys. 1994, 49, 14251-14269. 
(71) Kresse, G.; Furthmüller, J. Efficient Iterative Schemes for Ab Initio Total-Energy Calculations Using a Plane-Wave Basis Set. Phys. Rev. B: Condens. Matter Mater. Phys. 1996, 54, 11169-11186.

(72) Kresse, G.; Furthmüller, J. Efficiency of Ab-Initio Total Energy Calculations for Metals and Semiconductors Using a Plane-Wave Basis Set. Comput. Mater. Sci. 1996, 6, 15-50.

(73) Kresse, G.; Joubert, D. From Ultrasoft Pseudopotentials to the Projector Augmented-Wave Method. Phys. Rev. B: Condens. Matter Mater. Phys. 1999, 59, 1758-1775.

(74) Kresse, G.; Hafner, J. Ab Initio Molecular Dynamics for Liquid Metals. Phys. Rev. B: Condens. Matter Mater. Phys. 1993, 47, 558-561.

(75) Grimme, S.; Antony, J.; Ehrlich, S.; Krieg, H. A Consistent and Accurate Ab Initio Parametrization of Density Functional Dispersion Correction (DFT-D) for the 94 Elements H-Pu. J. Chem. Phys. 2010, $132,154104$.

(76) Grimme, S.; Ehrlich, S.; Goerigk, L. Effect of the Damping Function in Dispersion Corrected Density Functional Theory. J. Comput. Chem. 2011, 32, 1456-1465.

(77) Henkelman, G.; Uberuaga, B. P.; Jónsson, H. A Climbing Image Nudged Elastic Band Method for Finding Saddle Points and Minimum Energy Paths. J. Chem. Phys. 2000, 113, 9901-9904.

(78) Henkelman, G.; Jónsson, H. Improved Tangent Estimate in the Nudged Elastic Band Method for Finding Minimum Energy Paths and Saddle Points. J. Chem. Phys. 2000, 113, 9978-9985.

(79) Bader, R. F. W. Atoms in Molecules: A Quantum Theory. Atoms in Molecules: A Quantum Theory; Clarendon Press, 1994.

(80) Tang, W.; Sanville, E.; Henkelman, G. A Grid-Based Bader Analysis Algorithm without Lattice Bias. J. Phys.: Condens. Matter 2009, 21, 084204.

(81) Sanville, E.; Kenny, S. D.; Smith, R.; Henkelman, G. Improved Grid-Based Algorithm for Bader Charge Allocation. J. Comput. Chem. 2007, 28, 899-908.

(82) Henkelman, G.; Arnaldsson, A.; Jónsson, H. A Fast and Robust Algorithm for Bader Decomposition of Charge Density. Comput. Mater. Sci. 2006, 36, 354-360.

(83) Yu, M.; Trinkle, D. R. Accurate and Efficient Algorithm for Bader Charge Integration. J. Chem. Phys. 2011, 134, 064111.

(84) Manz, T. A.; Limas, N. G. Chargemol, a program for performing DDEC analysis. See the following: http://ddec.sourceforge.net/.

(85) Manz, T. A.; Limas, N. G. Introducing DDEC6 Atomic Population Analysis: Part 1. Charge Partitioning Theory and Methodology. RSC Adv. 2016, 6, 47771-47801.

(86) Limas, N. G.; Manz, T. A. Introducing DDEC6 Atomic Population Analysis: Part 2. Computed Results for a Wide Range of Periodic and Nonperiodic Materials. RSC Adv. 2016, 6, 4572745747.

(87) Manz, T. A. Introducing DDEC6 Atomic Population Analysis: Part 3. Comprehensive Method to Compute Bond Orders. RSC Adv. 2017, 7, 45552-45581.

(88) Dronskowski, R.; Bloechl, P. E. Crystal Orbital Hamilton Populations (COHP): Energy-Resolved Visualization of Chemical Bonding in Solids Based on Density-Functional Calculations. J. Phys. Chem. 1993, 97, 8617-8624.

(89) Deringer, V. L.; Tchougréeff, A. L.; Dronskowski, R. Crystal Orbital Hamilton Population (COHP) Analysis as Projected from Plane-Wave Basis Sets. J. Phys. Chem. A 2011, 115, 5461-5466.

(90) Maintz, S.; Deringer, V. L.; Tchougréeff, A. L.; Dronskowski, R. Analytic Projection from Plane-Wave and PAW Wavefunctions and Application to Chemical-Bonding Analysis in Solids. J. Comput. Chem. 2013, 34, 2557-2567.

(91) Maintz, S.; Deringer, V. L.; Tchougréeff, A. L.; Dronskowski, R. LOBSTER: A Tool to Extract Chemical Bonding from Plane-Wave Based DFT. J. Comput. Chem. 2016, 37, 1030-1035.

(92) Maintz, S.; Esser, M.; Dronskowski, R. Efficient Rotation of Local Basis Functions Using Real Spherical Harmonics. Acta Phys. Pol., B 2016, 47, 1165.

(93) Landrum, G. A.; Dronskowski, R. The Orbital Origins of Magnetism: From Atoms to Molecules to Ferromagnetic Alloys. Angew. Chem., Int. Ed. 2000, 39, 1560-1585.
(94) Hoffmann, R. Interaction of Orbitals through Space and through Bonds. Acc. Chem. Res. 1971, 4, 1-9.

(95) Börnsen, N.; Meyer, B.; Grotheer, O.; Fähnle, M. E Cov - a New Tool for the Analysis of Electronic Structure Data in a Chemical Language. J. Phys.: Condens. Matter 1999, 11, L287-L293.

(96) Grechnev, A.; Ahuja, R.; Eriksson, O. Balanced Crystal Orbital Overlap Population - A Tool for Analysing Chemical Bonds in Solids. J. Phys.: Condens. Matter 2003, 15, 7751-7761.

(97) Atkins, P.; Overton, T.; Weller, M.; Armstrong, F.; Hagerman, M. Inorganic Chemistry, 5th ed.; Oxford University Press, 2010; p 296.

(98) Hwang, B.; Chon, H. Interaction of Furans and Thiophenes with $\mathrm{Cu}$ (II) - Exchanged ZSM-5 and Y Zeolites. Zeolites 1990, 10, 101-104.

(99) Housecroft, C.; G. Sharpe, A. Inorganic Chemistry, 3rd ed.; Pearson, 2008; p 613.

(100) Goldstein, E.; Beno, B.; Houk, K. N. Density Functional Theory Prediction of the Relative Energies and Isotope Effects for the Concerted and Stepwise Mechanisms of the Diels-Alder Reaction of Butadiene and Ethylene. J. Am. Chem. Soc. 1996, 118, 6036-6043.

(101) Houk, K. N. Generalized Frontier Orbitals of Alkenes and Dienes. Regioselectivity in Diels-Alder Reactions. J. Am. Chem. Soc. 1973, 95, 4092-4094. 